University of Wollongong

Research Online

Australian Institute for Innovative Materials -

Papers

Australian Institute for Innovative Materials

$1-1-2015$

Electroactive biocompatible materials for nerve cell stimulation

Mei Yang

Wenzhou Medical University

Youlong Liang

Wenzhou Medical University

Qingyuan Gui

Wenzhou Medical University

Jun Chen

University of Wollongong, junc@uow.edu.au

Yong Liu

Wenzhou Medical University, Macquarie University

Follow this and additional works at: https://ro.uow.edu.au/aiimpapers

Part of the Engineering Commons, and the Physical Sciences and Mathematics Commons

Research Online is the open access institutional repository for the University of Wollongong. For further information contact the UOW Library: research-pubs@uow.edu.au 


\title{
Electroactive biocompatible materials for nerve cell stimulation
}

\author{
Abstract \\ In the past decades, great efforts have been developed for neurobiologists and neurologists to restore \\ nervous system functions. Recently much attention has been paid to electrical stimulation (ES) of the \\ nervous system as a potential way to repair it. Various conductive biocompatible materials with good \\ electrical conductivity, biocompatibility, and long-term ES or electrical stability have been developed as \\ the substrates for ES. In this review, we summarized different types of materials developed in the purpose \\ for ES of nervous system, including conducting polymers, carbon nanomaterials and composites from \\ conducting polymer/carbon nanomaterials. The present review will give our perspective on the future \\ research directions for further investigation on development of ES particularly on the nerve system.

\section{Keywords} \\ materials, nerve, cell, stimulation, biocompatible, electroactive \\ Disciplines \\ Engineering | Physical Sciences and Mathematics

\section{Publication Details} \\ Yang, M., Liang, Y., Gui, Q., Chen, J. \& Liu, Y. (2015). Electroactive biocompatible materials for nerve cell \\ stimulation. Materials Research Express, 2 (4), 1-14.
}




\section{Electroactive Biomaterials for Nerve Cell Stimulation}

Mei Yang, ${ }^{1}$ Youlong Liang, ${ }^{1}$ Qingyuan Gui, ${ }^{1}$ Jun Chen ${ }^{2, *}$ and Yong Liu ${ }^{1, *}$

${ }_{5}{ }^{1}$ Institute of Advanced Materials for Nano-Bio Applications, School of Ophthalmology \& Optometry

Wenzhou Medical College, Wenzhou, Zhejiang 325027, China

${ }^{2}$ ARC Centre of Excellence for Electromaterials Science, Intelligent Polymer Research Institute

University of Wollongong, Northfields Avenue, Wollongong, NSW 2522, Australia

10

*Corresponding authors:

Dr. Jun Chen

University of Wollongong, Northfields Avenue

${ }_{30}$ Wollongong, NSW 2522, Australia,

Email: junc@uow.edu.au

Phone: +61 42213781

Fax: +6142213781

${ }_{35}$ Prof. Yong Liu

Vision Research Centre, Wenzhou Medical College

270 Xueyuan Xi Road, Wenzhou, Zhejiang 325027, China

Email: yongliu1980@ hotmail.com

Phone: +86 57788067973

${ }_{40}$ Fax: +86 57788067973 


\section{Abstract}

In the past decades, though surgery techniques have been improved greatly, the clinical results of nerve repair still remain unsatisfactory due to the complexity of the nervous system anatomy and function. Thus, great efforts have been developed for neurobiologists and neurologists to restore nervous system function. Recently many attentions have been paid on electrical stimulation on the nervous systems as a potential way to repair nervous system. Various ${ }_{50}$ conductive biomaterials with good electrically conductivity, biocompatibility, ideally biodegradability, and long-term electrical stimulation or electrical stability have been developed as the substrates for electrical stimulation. In this review, we summarized different types of biomaterials developed in the purpose for applications as electrodes in the electrical stimulation of nervous systems, including conducting polymers, carbon nanomaterials and composites from conducting polymer/carbon nanomaterials. The present research will give our perspective on the future research ${ }_{55}$ directions with the purpose for further investigation on developments of the.electical stimulation particularlly on the nerve systems.

60

Keywords: Nerve Cell Stimulation, Biomaterials, Conducting Polymers, carbon nanomaterials, Nano-Composites. 


\section{INSTRUCTION}

70 Nerve tissue engineering (NTE) is one of the most promising methods to restore central nerve systems in human health care. Nowadays, neural diseases are considered as complicated and significant clinical problems in the world with increasing age and polulation.

75 Demand on various neural implants is necessary. It is however, a big challenge for nerve repaire when compared to other tissue repairs (such as bone repair) due to the complexity of the nervous system anatomy and function. Comparing with peripheral nervous system (PNS, such as 80 spinal and autonomic nerves), the central nervous system (CNS, such as the brain and spinal cord) cannot be regenerated by itself after trauma or disease, because it lacks Schwann cells to promote axonal growth and the thick glial scar tissue which may result in an unfavorable 85 environment inhibiting neural regeneration [1-4]. Therefore, restoring its function became a challenge for neurobiologists and neurologists. In general, there are mainly two strategies to repair the nervous system. One is the use of biomaterials as cell carriers for cell replacement

90 therapies, including the use of biomaterials as scaffolds to replace natural ECM and to support axonal growth. The aother way is the use of biomaterials as drug delivery devices. Traditionally, tissue transplantation or peripheral nerve grafting are mainly used to repair damaged or ${ }_{95}$ diseased regions at the CNS (such as using autografts, allografts, xenografts, and silicon probes for the continuous diagnosis and treatment of neural tissue and other biomaterial nerve graft devices). A variety of problems, however, can not be ignored since this technique could't 100 satisfy the high performance demands, such as the lack of donor nerves [4-6], the risk of transmitting diseases and the foreign body response and so on [7-9].

Electrical stimulation of the nervous system has been considered as a good approach to ameliorate conditions 105 such as epilepsy, Parkinson disease, depression, hearing loss and chronic pain. It is known that bioelectricity present in the human body plays an integral role in maintaining normal biological functions such as signaling of the nervous system, muscle contraction, and wound 110 healing [10]. Upon exposure to electric fields, one side of the cell becomes hyperpolarized while the opposite side is depolarized [11]. Fundamental physiological processes can be catalyzd by electric potential differences across biological membranes. This synergistic effect between ${ }_{115}$ electrical stimulation and neurotrophin delivery can increase the number of Trk receptors expressed on the cell surface, facilitating a larger effect of neurotrophins $[12,13]$. The representation of electrical stimulation was shown in Figure 1 [14]. Additionally, cellular activities 120 such as cell migration [15], cell adhesion [17], DNA synthesis $[17,18]$ and protein secretion can be modified by electrical stimulation [19]. These characteristics make electrical stimulation become attractive in therapies for various neurological diseases and significant in tissue ${ }_{125}$ engineering since regulating cellular activities in an artificial scaffold is of great importance with respect to controlling the regeneration of damaged tissues. Presently, electrical stimulation has been successfully utilized in some clinic cases such as deep brain stimulators [15, 16] 130 and cochlear implants [17-19], which was used to reduce symptoms of Parkinson's disease and restore auditory function, respectively. Medical applications of neural electrodes, e.g. the treatment of retinitis pigmentosa [20], epilepsy [21], depression [22] and chronic pain [23], have 135 also been reported. The therapy efficiency is highly depended on the quality of the neuron-electrode interface. A universal interface with high selectivity, sensitivity, good charge transfer and long-term chemical and recording stability is a great challenge for nerve 140 regeneration.

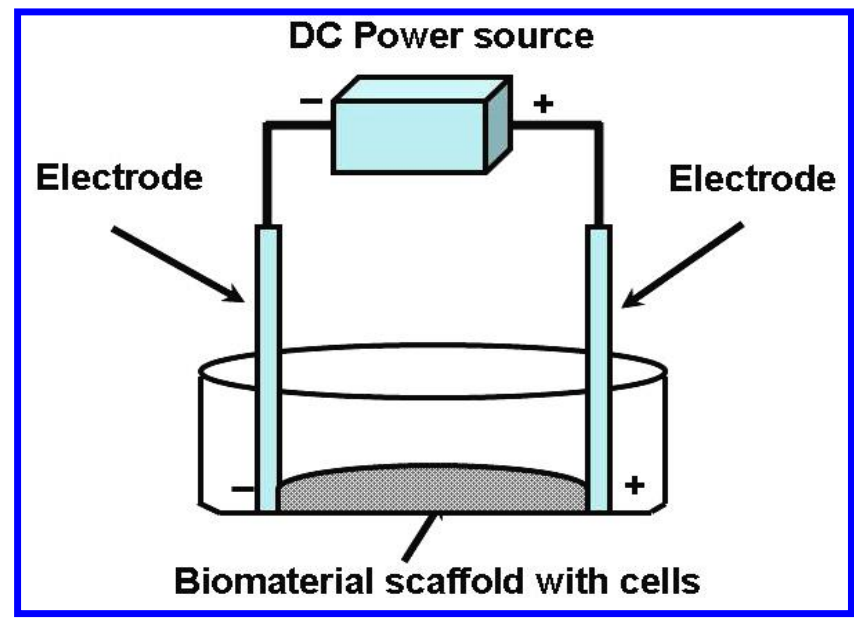

Figure 1. Schematic representation of electrical stimulation. Adapted from Ref. [14].

145 Neural electrodes, normally in electrode arrays, are the key elements in long-term implantable neural prostheses. The electrically conducting materials may benefit neural repair in the form of scaffolds implanted within lesion cavities to provide mechanical support and 150 spatially arranged molecular cues for regenerating neurons [24]. Electrical stimulation via the scaffold would activate the molecular machinery necessary for axon elongation either by inducing nerve action potentials [25] or multicellular healing responses [26]. These materials 155 should be electrically conductive, biocompatible, and ideally biodegradable, long-term electrical stimulation or electrical stability. Nowadays, most neural electrodes are mainly from considerably stable metals e.g. platinum, gold, iridium, titanium and stainless steel. Pt is one of the most 160 popular candidates for neural electrodes due to its unique properties [27]. The maximum safe charge injection $\left(Q_{\text {inj }}\right)$ limit for $\mathrm{Pt}$ electrodes, however is only about 0.15 $\mathrm{mC} / \mathrm{cm}^{2}$, which limits its futher application in neural microelectrodes [28]. Futhermore, metallic electrodes are 165 often suffering from poor performance in long-term stimulation and recording due to poor contact with tissue or scar formation. Numerous surface modification techniques was thus developed to improve the electrode performance. For example, Though Iridium oxide ( $\mathrm{IrOx}$ ) 170 was generally used as the coating material for neural 
electrodes [29-32], application of IrOx was still limited by its poor adhesion to underlying substrates and degradability under chronic aggressive stimulations due to its low structural and chemical stability $[33,34]$. This may 175 cause tissue damage and aggravate inflammatory responses. Uilisation of these microelectrodes in the long-term in vivo are still need to be investigated further.

In the past few decades, development of conducting polymers (CP) and carbon nanomaterials (CNTs) have 180 attracted for great attention in many application areas such as energy storage, drug delivery, and bio/chem-sensors, considering their unique electrical and chemical properties [35-37]. Recently, employments of CP and CNTs in the the area of implantable neural electrodes have been 185 attracted for increasing attention. Great efforts have been paid in preparation of novel biomaterials with high electrically conductivity, good biocompatibility, and ideal biodegradability, and long-term electrical stimulation or electrical stability. In this review, we will summarize 190 recent efforts on developments of CP and CNTs as neural electrodes, providing new directions and useful information for clinical application.

\section{Conducting Polymers}

195 Electrically conductive polymers, known as synthetic metals, are widely investigated and studied in various applied chemistry and physics fields since they could simultaneously possess physical and chemical properties of organic polymers and the electrical characteristics of 200 metals [38]. Recently, conducting polymers (CPs) attract considerable interests for numerous biomedical applications in tissue engineering, such as attachment, proliferation, migration, and differentiation modulated through electrical stimulation [39]. Normally, CPs possess

205 a conjugated backbone with a high degree of p-orbital overlap, which can be readily oxidized or reduced to become either positively charged (oxidative or $\mathrm{p}$-type) or negatively charged (reductive or n-type) through a "doping" process, respectively [40]. CPs can be 210 electrochemically deposited on neural electrodes with well-defined and controlled thickness. Different bioactive molecules can also be subsequently incorporated into the polymer matrix as a dopant or via physical penetration to promote neuronal growth and adhesion to the electrode 215 surface [41, 42]. Up to now, various biodegradable synthetic polymers [43, 44], peptide copolymers [45], and natural proteins [46-48] have been synthesized for various biomedical applications, such as tissue engineering [4952], wound dressing [53], drug delivery [54], and vascular ${ }_{220}$ grafts [55]. Various type of conductive polymers including polypyrrole (PPy), polyacetylene, polythiophene, polyaniline (PANi), poly(3,4-ethylenedioxythiophene) (PEDOT), and poly(para-phenylene vinylene) have been fabricated and investigated.

${ }_{225}$ Polypyrrole (PPy) and its derivatives are the most widely utilized $\mathrm{CP}$ in tissue engineering due to its good electrical conductivity, biocompatibility, high electrical stability, and ease of synthesis [56]. The reduction and oxidation of PPy is a reversible redox process, as shown in ${ }_{230}$ Figure 2 [57]. It has already been studied for many industrial applications [58-61] particularly in biomedical field [62, 63]. For example, PPy coated polyester fabrics have found to be good biocompatible both in vitro and in vivo, suggesting its potential applications in bio-medics. ${ }_{235}$ Conductive PPy film has shown to support the proliferation of nerve cells [64, 65], chromaffin cells [66], and endothelial cells [67]. Schmidt and coworkers first found out that electrical stimulation of PPy films could enhance NGF induced neuronal differentiation of PC 24012 cells, which was probably mediated by the fibronectin adsorption boosted by an electrical field [68]. Subsequently, Schmidt's group functionalized the surface of chlorine-doped PPy to anchor peptide molecules that could significantly promote nerve regeneration, blood 245 vessel growth, and other biological processes [69]. Lakard et al. cultured olfactory cells on PPy to investigate cell adhesion and proliferation [70]. George et al. examined biocompatibility of PPy and found neurons and glial cells enveloped the PPy implant [71]. Several other scaffolds 250 containing PPy have been used for various applications of tissue engineering [72, 73]. For an instance, conductive nanofibrous scaffolds from PPy coated poly (styrene-bisobutylene-b-styrene) nanofibrous have shown a good proliferation of PC12 (Figure 3) by Liu et al. [74].

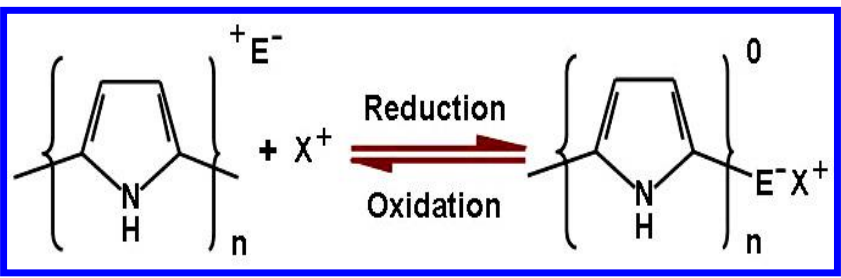

Figure 2. Reversible conversion between the reduction and oxidation states of PPy. Adapted from Ref. [57].

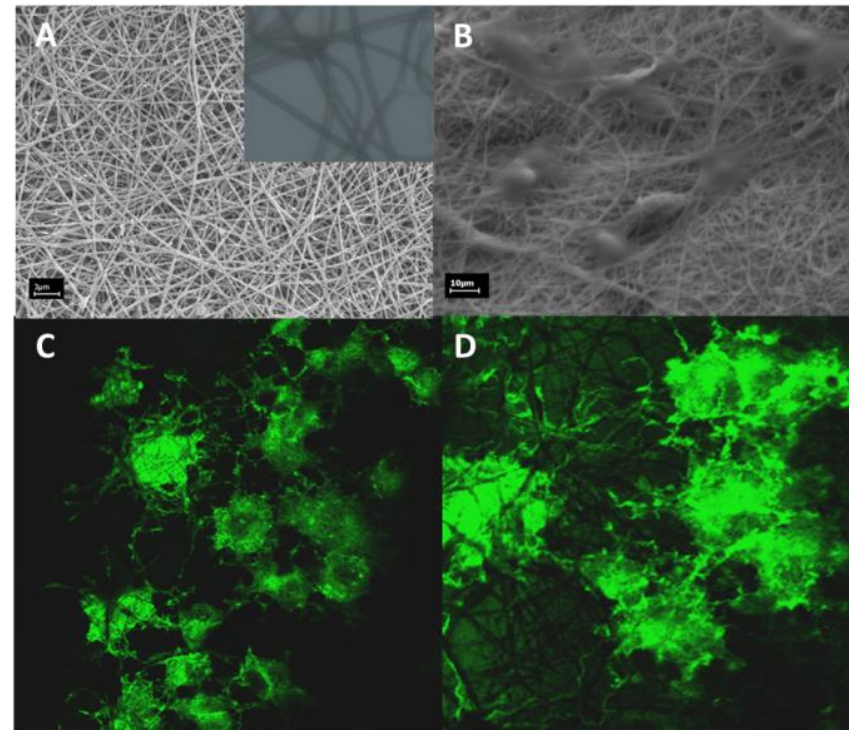

${ }_{260}$ Figure 3. SEM images of (a) PPy/SIBS nanofibres platform, (b) PC12 on PPy/SIBS mat, and (c\&d) fluorescence microscope image of phalloidin stained PC12 cells grown on SIBS/PPy nanofibres. 
However, the applicability as a biomaterial of PPy was ${ }_{265}$ limited by the poor mechanical properties, lack of biodegradability, and difficulties in processing it into complex three-dimensional structures [75]. Therefore, great efforts were paid to combine PPy with other materials that possess the desired material properties to 270 obtain hybrid composites. Various PPy composites have been studied by introduction different types of synthetic polymers with good biocompatibility and mechanical properties, bioresorable degradation products and adjustable degradation rate. These polymers include 275 poly(methyl methacrylate) [76, 77], polyvinylchloride [78], polystyrene [79], polyurethane [80] and poly(a-hydroxy acid) [81-85]. Durgam et al. synthesize a block copolymer composed of PPy and PCL [86], which demonstrated good conductivity, biodegradability, and the ability to support ${ }_{280} \mathrm{PC} 12$ cell proliferation. While Bao et al. reported that electrical stimulation on the electrospun PLGA/PPy nanofiber mat to PC 12 cells resulted in an increase in the number and length of neurite extensions [87]. Huang et al. measured electrical stimulation on the biodegradable ${ }_{285}$ chitosan-PPy composite to Schwann cells to electrical stimulation (ES) and found the enhanced cell proliferation and increased neurotrophin secretion [88]. Moroder et al. synthesized polycaprolactone fumarate-polypyrrole (PCLF-PPy) scaffolds with excellent mechanical 290 properties, which were found to be significantly able to increase the percentage of neurite bearing cells via controlled electrical stimulation [89].

Another popular CP, polyaniline (PANI) and its variants have also been studied in wide range of research areas due 295 to their unique properties such as the various oxidative state, ease of synthesis, low cost, conductivity and environmental stability $[90,91]$. PANI has also shown good biocompatibility in vivo with the ability to support cell growth, suggesting potential interests in tissue 300 engineering applications [95-99]. Mattioli-Belmonte et al. demonstrated for the first time that PANi is biocompatible both in vitro and in vivo [99]. Electrical stimulation of nerve cells on PANI substrates have been studied by many research groups [100-102]. H9c2 rat cardiac myoblast on ${ }_{305} \mathrm{PANI} /$ gelatin nanofibrous scaffolds has been investigated by $\mathrm{Li}$ et al. [103]. $\mathrm{Li}$ and coworkers prepared biocompatible fibrous blend of conductive camphorsulfonic acid-doped emeraldine PANi (C-PANi) with gelatin showing to support the proliferation of $\mathrm{H} 9 \mathrm{c} 2$ 310 rat cardiac myoblasts [104]. Jeong et al. investigated the cell adhesion on electrospun PANI/poly (L-lactide-coecaprolactone) (PLCL) scaffolds and applied electrical stimulation to NIH-3T3 fibroblasts [105]. GhasemiMobarakeh et al. fabricated conductive PANI/PG 315 nanofibrous scaffolds by electrospinning. The electrical stimulation of NSCs through conductive nanofibrous scaffolds enhanced the cell proliferation and neurite outgrowth more significantly than the nonstimulated scaffolds, indicating that they are suitable substrates for 320 nerve tissue engineering [106].

Compared with PPy and PANi, poly $(3,4$ ethylenedioxythiophene) (PEDOT) is the other popular conducting polymer due to its ordered and well-defined chemical structure, which exhibits outstanding 325 conductivity, stability, fast response time, small electronic band gap (Eg 1/4 1.6eV, 775nm), low redox potentials, and facile fabrication in a doped form [107-110]. Recently, researchers have demonstrated the ability to dramatically improve the electrical properties of neural $[111,112]$ and 330 cochlear electrodes by surface modification with PEDOT [113]. Cui and Hendricks have reported that the electrical properties of neural electrodes can be significantly improved by surface coating with PEDOT $[111,113]$. In additions, various methods have been explored to improve 335 biocompatibility and drug release capabilities of the PEDOT films. Despite its advantages and well-defined outlook, conventional PEDOT films still need to improve their physical and chemical properties in order to be a promising coating material for neural electrodes. Cui and ${ }_{340}$ Jan have indicated that the long-term stability of PEDOT coatings during chronic electrical stimulation was not satisfied $[111,114]$. As PEDOT coatings may form cracks or delaminate under stimulation, which could lead to further coating detachment and debilitating the function of 345 the electrode. SH-SY5Y neuroblastoma cells were found to grow and adhere well on the conductive and electroactive 3D-scaffolds from electrospun PEDOT-pTs coated fibers by Maria [115]. Collazos-Castro et al. reported the combination of electrochemical and molecule self350 assembling methods to consistently control neural cell on PEDOT doped with polystyrene sulfonate (PEDOT:PSS), while maintaining very low interfacial impedance [116]. Neurite extension was strongly inhibited by an additional layer of PSS or heparin, which could be either removed 355 electrically or further coated with spermine to re-activate cell growth. Binding basic fibroblast growth factor (bFGF) to the heparin layer inhibited neurons but promoted proliferation and migration of precursor cells. This method provides a potential way to control neural cell behavior on 360 electro active polymers via improving cell/electrode communication in prosthetic devices, and to develop a platform for tissue repair strategies. 


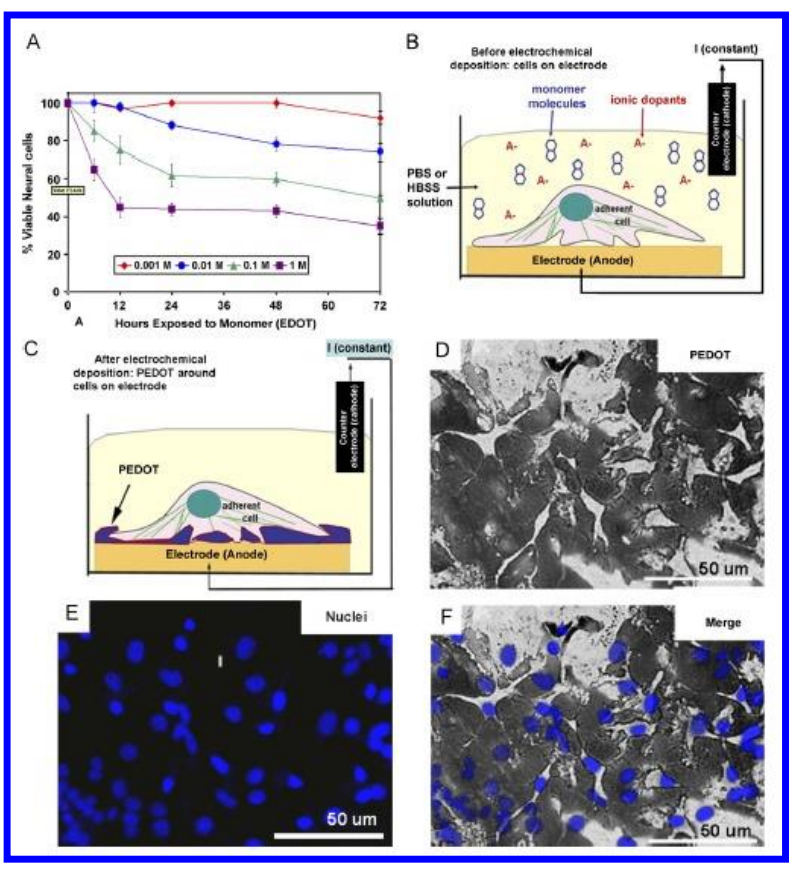

365

Figure 4. (A) MTT cytotoxicity assay for exposure of SY5Y neural cells to increasing concentrations of EDOT in monomer solution (all with $0.02 \mathrm{M}$ PSS) for 0-72 h. (B) Diagram representing the electrochemical deposition cell 370 and the neural cell monolayer cultured on the surface of the metal electrode prior to polymerization. (C) Diagram representing PEDOT polymerized around living cells. (D) PEDOT (dark substance) polymerized in the presence of a monolayer of SY5Y neural cells cultured on an $\mathrm{Au} / \mathrm{Pd}$ 375 electrode. (E) Nuclei of SY5Y cells stained with Hoechst 33342 (blue florescence). (F) Merged image showing nuclei of cells around which PEDOT is polymerized.

Besides above three main CPs (PPy, PANi, and 380 PEDOT), there are also other kinds of conducting polymers, such as Poly(L-lactic acid) (PLLA), which possesses good mechanical integrity, biodegradability and biocompatibility. It has also been utilized for fabrication of scaffolds for nerve regeneration with longer degradation 385 behaviors [117]. PLLA microfilaments used as structural support for long lesion nerve gap regeneration have also been reported [118]. Yang et al. fabricated nano-structured PLLA scaffolds, which can facilitate NSCs differentiation and neurite outgrowth in great degree [119]. Molamma et 390 al. reported the synthesis PLLA/PANi nanofibers using electrospinning can enhance the neurite outgrowth under electrical stimulations, providing possibility for application of electrical stimulation as a potential clue for nerve tissue regeneration [120].

\section{3. Carbon nanomaterials}

Carbon nanotubes (CNTs), an important type of carbon nanomaterials, are cylindrical structures having high aspect ratios with long axial lengths (up to millimeters) and a few Ångströms in diameter. They are tough and robust 400 materials with ultimate electrical and thermal conductivities and mechanical strength. These carbon hollow nanomaterials can be viewed as "rolled-up", structures of one or more layers of graphene sheets for single-walled (SWNT) or multiple-walled (MWNT) 405 carbon nanotubes, respectively. The unique mechanical, chemical and electrical properties of CNTs provide a wide range of opportunities and potential applications in biology, medicine industry, which allow them to be one of the most promising materials for application in neural Prosthesis $410[121]$.

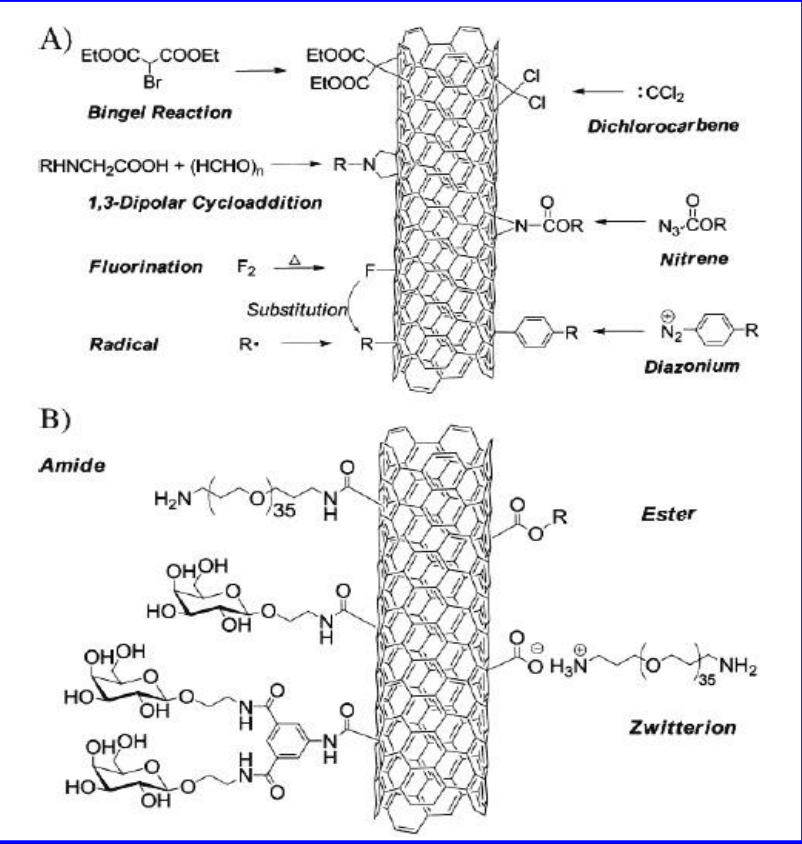

Figure 5. A) Covalent addition reactions on the sidewall of carbon nanotubes. B) Reactions targeting carboxylic acids

${ }_{415}$ (derived from nanotube surface defects). Adapted from Ref. [130].

Recently, great efforts have been developed in biological applications of CNTs at molecular and cellular levels, such as nanoscale biosensors [122, 123], 420 electroanalytical nanotube devices [124], electromechanical actuators for artificial muscles [125, 126], and laser heating cancer therapy [127]. Futhermore, unique properties of CNTs such as diameter and aspect ratios similar to neural processes such as dendrites, good 425 mechanical strength with flexibility, make them be able to maintain scaffolds' structural integrity during cell growth. Good conductivity of the CNTs based scaffold can provide extra advantages for electrical stimulation. Additionally CNTs can also be used in vivo devices that could directly 430 interact with neurons. All these unique propertiess make CNTs well suited in the design of novel neural biomaterials [128].

For well applications in neural regeneration, a good scaffold should not only conduct electrical current but also ${ }_{435}$ support neuron growth. The functionalization of CNTs or CNF-based scaffolds can provide further advantages such as improvement in bioactivity, and conjugation with various functional groups such as bioactive agents, nucleic 
acids and therapeutic agents [129]. Figure 4 exhibited 440 various methods for functionalization of CNTs with different functional groups such as bioactive agents, nucleic acids and therapeutic agents after being functionalization [130] .

Mattson et al. studied for the first time in application of 445 carbon nanotube technology to neuroscience research. They found that neurons extend only one or two neuritis on unmodified nanotubes, which exhibit very few branches. After incorporation of CNTs with the bioactive molecule 4-hydroxynonenal (4-HNE) used as scaffold, neuritis ${ }_{450}$ exhibit extensive branching [131]. These results provide possibility for using nanotubes as substrates for nerve cell growth and as probes of neuronal function at the nanometer scale. Hu et al. reported that the control of neurite outgrowth by manipulating the charge carried by

455 functionalized CNTs [132]. Gaby et al. realized neuronal cell patterning using nano-topography constructed with islands of high-density fabrics made of CNTs [133]. These results suggest that CNTs are biocompatible as neuronal substrates and have potential applications in neural ${ }_{460}$ prostheses. Anava et al. and Sorkin et al. have developed a unique carbon-nanotube (CNT) based MEA in which the CNT electrodes are used to position and stabilize the cells and the network between the neurons and the CNTs, respectively [134, 135]. The highly-conductive CNTs can 465 be used as recording and stimulation sites, forming an optimized interface with the neurons to achieve long-term electrical recordings. Moreover, Greenbaum et al. reported a new result about using specially designed CNT substrates to pattern predefined small size networks of locust frontal ${ }_{470}$ ganglion neurons and record their electrical activity [136].

CNTs were also considered as a good candidate for implants due to the good stability and non-biodegradation, making the effect studies of CNTs on neurons to be very necessary. So far, many efforts have been made on it.

${ }_{475}$ Lovat et al's recent report demonstrated that purified CNTs are ideal sustrates for the growth of neurons and helpful for the enhancement in the efficacy of neural signal transmission [137]. Authors attributed the increase in the efficacy of neural signal transmission to the specific 480 properties of CNTs, which provided a pathway allowing direct electrotonic current transfer, and causing a redistribution of charge along the surface of the membrane. This result can be attibuted to the reinforcement of a direct electrical coupling between neurons. Meanwhile, Cui et al. 485 found that SWCNTs inhibited the proliferation of HEK293 cells (human embryo kidney cells) by decreasing their cell adhesiveness in a dose- and time dependent manner [138]. Cellot and co-workers further investigated the efficiency of signal transmission of neurons grown on a conductive ${ }_{490}$ nanotube meshwork. Their results provide a new mechanistic insight into how nanotubes target the integrative properties of neurons. Authors proposed a mathematical model to explain phenomena and consequences for the enhanced signal transmission of

495 neurons cultured on nanotube substrate, linking the electrical phenomena in nanomaterials to neuronal excitability for the first time [139]. Mazzatenta et al. developed an integrated SWNT-neuron system to test whether electrical stimulation delivered via SWNT can 500 induce neuronal signaling. Hippocampal cells were grown on pure SWNT substrates and patch clamped [140]. Results indicate that SWNTs can directly stimulate brain circuit activity and facilitate to understand the electrical coupling between neurons and SWNT. Fabbro et al. ${ }_{505}$ reported that direct nanotube-substrate interactions with the membranes of neurons would affect single neuron activity and promote network connectivity and synaptic plasticity in mammalian cortical circuits in culture [141, 142]. Moreover, they used organotypic cultures of the 510 embryonic mouse spinal cord interfaced with CNT scafolds to investigate whether and how the interactions at the monolayer level are translated to multilayered nerve tissues. The results indicated that the effects rely on direct and indirect MWCNT interactions [143]. Matsumoto et al. 515 reported that low concentrations of functionalized CNTs modified by amino groups could promote outgrowth of neuronal neurites in dorsal root ganglion (DRG) neurons and rat pheochromocytoma cell line PC12h cells in culture media. In addition, they investigated the signal ${ }_{520}$ transduction pathways (extracellular signal-regulated kinase (ERK) signaling pathway and Akt signaling pathway) stimulated by CNTs [144].

Two (2D) and three (3D) dimensional architectures with interconnected cavities composed of CNTs also could be ${ }_{525}$ used in envisioning cell growth and tissue modeling, as shown in Figure 5 using 3D Aligned CNTs/SIBS platform. Many studies have investigated the cellular response to carbon nanofibers/nanotubes including dose-dependent effect $[145,146]$. Correa-Duarte created a 3D network 530 based on an array of interconnected MWCNTs [147]. They found that the common mouse fibroblast cell line L929 can extensive grow, spread, and adhere on the MWCNT substrate, indicating that the 3D MWCNT network was a good candidate for scaffolds/matrices in tissue engineering.

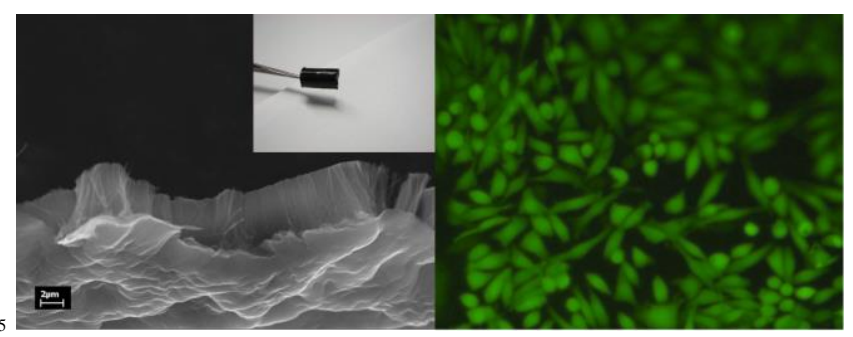

Figure 6. Left - SEM image of ACNTs/SIBS; and Right L-929 cell culture on 3D ACNTs/SIBS platform.

As a fiberious carbon nanomaterial, carbon nanofibers (CNFs) have drawn much attention in creating interfaces 540 between electrodes and neural tissues in electrical stimulation due to their unique properties, such as chemical stability, ultramicro size, low electrical impedance, 3D structures with high surface-to-volume ratio, and longterm biocompatibility. CNFs can provide a large active ${ }_{545}$ surface area for neural recording and stimulation while individual electrode sites on the substrate are scaled down. $\mathrm{Li}$ and co-workers reported a series of advancements in developing 3D brush-like vertically aligned carbon 
nanofiber (VACNFs) [148-150]. They fabricated VACNFs ${ }_{550}$ on a silicon wafer by plasma enhanced chemical vapor deposition using $\mathrm{Ni}$ as catalyst, and tested them with PC12 cells. The results indicated that the soft 3D VACNFs architecture provided a new platform to fine-tune the topographical, mechanical, chemical and electrical cues at 555 subcellular nanoscale. Yu et al. developed a CNF-based neural chip and demonstrated its capability of both stimulating and recording electrophysiological signals from brain tissues in vitro [151, 152]. In this study, longterm potentiation (LTP) was induced and detected through

${ }_{560} \mathrm{CNFs}$ arrays. Park and co-workers developed thin-film transistor (TFT)-VACNFs MEA platform [153], in which they fabricated the VACNFs on an active matrix TFT. By using this new platform, stimulating and recording could also be realized simultaneously. VACNF integrated on the ${ }_{565}$ TFT array enhanced the electrical selectivity to the cell, and furthermore, they provided the potential for intracellular sensing within individual cells. McKnight et al. prepared two types of VACNF electrode arrays with high aspect ratios and tested neuronal cell (specifically, rat 570 phenochromocytoma, PC12 cells) differentiation on the VACNF substrates [154]. According to electro-analysis results at discrete electrodes after long term cell cultures, they founded that these CNF arrays were responsive for the detection of oxidized species generated by the cultured 575 cells. They also recorded spontaneous and induced neuroelectrical activity in organotypic hippocampal slice cultures with ultra microelectrode VACNF arrays [155], suggesiting that the carbon-based electrodes may be potentially superior to conventional metal electrodes.

${ }_{580}$ As a layered carbon nanomaterial, graphene, a fascinating 2-dimensional monolayer of carbon atoms, has recently emerged with many intriguing properties including electrical, thermal, optical, sensing, high surface area and biocompatibility. As the single or fewer layered 585 structure of graphene provides richness for diversified surface chemistry on both sides of the sheet including edges, significant progresses have been made for the utilization of grapheme in nanocomposites [156] and biological systems as well, such as detection of DNA and 590 metal ion [157, 158], protein and pathogen [159-161], design of cell/bacterial nanodevices [162-164] and drug delivery carriers $[165,166]$. Meanwhile, much attention has also been paid in designing novel neural biomaterials based on graphene for neural regeneration since neural 595 cells are electro-active and functions of nerve systems are related to electrical activities. As neuronal stimulation and monitor are needed for a variety of clinical diagnostics and treatments, unique electrical properties of graphene offer great advantages for the therapeutic or other purposes. ${ }_{600}$ Another reason for develping graphene based materials for neural regeneration is that the electronic properties of the nanostructured graphene can be tailored to match the charge transport required for electrical cellular interfacing. In addition, chemically stable properties of graphene ${ }_{605}$ facilitate the integration with neural tissues. For example, they can be used as neural chips, implanted electrodes and drug/gene vectors [167-169]. $\mathrm{Li}$ and co-workers demonstrated that graphene films grown from CVD have excellent biocompatibility for primary culture of mouse ${ }_{610}$ hippocampal neurons and are even capable of promoting neurite sprouting and outgrowth, especially during the early developmental phase [170]. In order to use human neural stem cells (hNSCs) for brain repair and neural regeneration, it is critical to induce hNSC differentiation 615 which is directed more towards neurons than glial cells [171-174]. However, most previous studies reported that hNSCs, without biochemical motifs or co-culturing, differentiated more towards glial cells than neurons [175177].

620

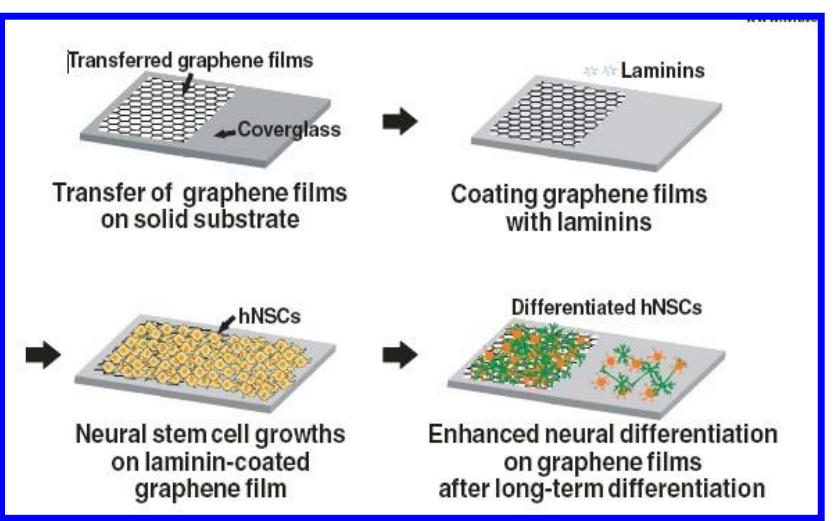

Figure 7. Schematic diagram depicting the growth and differentiation of hNSCs on graphene. Adapted from Ref. [178].

${ }_{625}$ Park et al. discovered that the neuronal differentiation of hNSCs on graphene was greatly enhanced under electrical stimulation [178]. In a typical research, as schematically shown in Figure 6, graphene worked as an excellent celladhesion layer and induced differentiation of hNSCs more ${ }_{630}$ toward neurons rather than glial cells, which would open up tremendous opportunities in stem cell research, neuroscience, and regenerative medicine. Authors also found that grapheme had a good electrical coupling with the differentiated neurons. Their results suggested that ${ }_{635}$ graphene ccould be used as excellent nanostructured scaffolds for promoting NSC adhesion and differentiation for long-term periods as well as possible neural prosthetics.

Heo et al. prepared a non-cytotoxic graphene/ polyethylene terephthalate (PET) film [179]. The transient ${ }_{640}$ non-contact electric field was produced by chargebalanced biphasic stimuli through the graphene/PET electrodes, which significantly increased the number of cells forming new cell-to-cell couplings and the number of cells strengthening existing cell-to-cell couplings. ${ }_{645}$ These findings may facilitate the development of a new therapeutic stimulator for neurological diseases and cell transplantation therapy in CNS. Feng and coworkers developed a reusable graphene-based electrochemical aptasensor for label-free cancer cell detection [180]. ${ }_{650}$ Typically, 3,4,9,10-perylene tetracarboxylic acid (PTCA), a water-soluble perylene derivative was strongly adsorbed on graphene through pep stacking and hydrophobic interactions was used to avoid graphene aggregation and 
introduce more negatively-charged $-\mathrm{COOH}$ groups on ${ }_{655}$ graphene surface, without further destroying the conjugated p-system of graphene.

So far, considerable progresses have already been made in the related fields, while solutions for many critical issues in neural biology/medicine are still underway due to 660 the availability of specialized nanomaterials.

\section{Carbon nanomaterials and conducting polymers composites}

The function and longevity of implantable ${ }_{665}$ microelectrodes for chronic neural stimulation depends greatly on the electrode materials or coatings with high charge injection capability and high stability. Though conducting polymers have been coated on neural microelectrodes and shown promising properties for ${ }_{670}$ chronic stimulation, their practical applications have been limited due to their drawbacks, e.g. the fragile characteristics, weak adhesion to the electrode substrate, and the poor electrochemical stability [181]. CNTmodified electrodes have exhibited good cytocompatibility 675 and stability, suggesting their possible applications as in vivo devices to interact directly with neurons. Their $\mathrm{Q}_{\mathrm{inj}}$, however, are found to be in the range much lower than IrOx electrodes, limiting their further applications.

Recent reports have shown that CNTs can be 680 incorporated into conducting polymers to prepare composite materials with enhanced properties, such as lower electrode impedance, higher capacitance and faster charge transfer rate as well as better mechanical stability [182]. Keefer and co-workers synthesized PPy/SWCNT ${ }_{685}$ deposited microelectrodes to record neural signals in vivo [183]. Peng et al. prepared composite films from CNTs and conducting polymers e.g. polyaniline (PANI), polypyrrole (PPy) or poly[3,4-ethylenedioxythiophene] (PEDOT). The composite films were prepared via ${ }_{690}$ electrochemical co-deposition from solutions containing acid treated CNTs and the corresponding monomers of conducting polymers [184]. The CNTs served as the charge carriers during electro-deposition, the backbone of a three-dimensional micro- and nano-porous structure and ${ }_{695}$ the effective charge-balancing dopant within the polymer. All composites showed improved mechanical integrity, higher electronic and ionic conductivity, and larger electrode specific capacitance than the pristine polymers. In the indentified conditions, the capacitance was enhanced 700 significantly after incoporation of conducting polymers with CNTs. Bhandari et al. fabricated composite films of of PEDOT-enwrapped functionalized multiwalled carbon nanotubes (MWCNTs) over multiple length scales by electropolymerization of the monomer without the use of 705 any other supporting electrolyte [185]. In this work, as schematically shown in Figure 7, the functionalized MWCNTs were incorporated into the positively charged polymer deposit as counterions during oxidative electropolymerization.

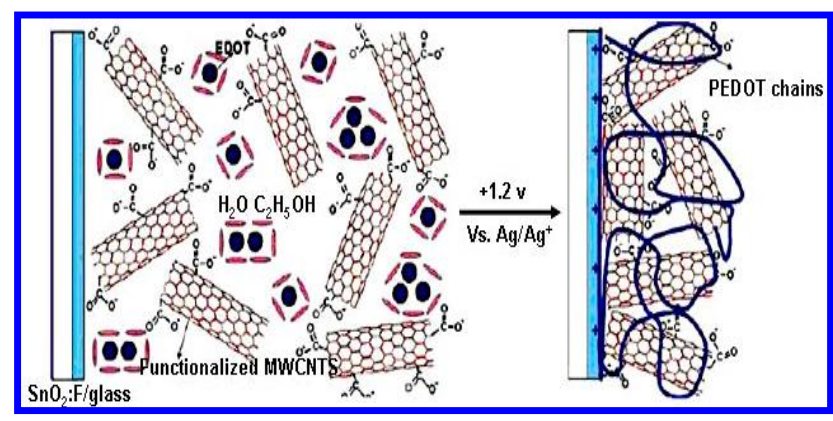

Figure 8. Schematic showing the formation of the PEDOTMWCNT film from the solution containing EDOT, functionalized MWCNTs in a mixture of polyethylene 715 glycol, water, and ethanol under a constant potential of +1.2 V. Adapted from Ref. [185].

$\mathrm{Lu}$ et al. investigated co-deposited PPy/SWCNT films on Pt for improving the electrode-neural tissue interface 720 which are suitable for the application of neural stimulating electrodes [186]. The PPy/SWCNT microelectrode exhibited a particularly high capacitance and lower impedance when compared to the $\mathrm{Pt}$ microelectrode. Introduction of SWCNT into conducting polymers 725 enhanced mechanical and electrochemical stabilities than the pristine conducting polymer films. Furthermore, the PPy/SWCNT film also showed excellent biocompatibility both in vitro and in vivo, suggesting possibilities for developing chronic implantable neural probes based on 730 conducting polymers and CNTs for the purpose of electrical neural microstimulation and recording. Luo et al. reported the synthesis of PEDOT/CNT composite electrochemically deposited on the $\mathrm{Pt}$ microelectrode arrays [187]. The resulting electrode exhibited much lower 735 impedance, higher charge storage capacity, and a high $Q_{\text {inj }}$ $\left(2.5 \mathrm{mC} / \mathrm{cm}^{2}\right)$. The resulting film also exhibited good stability under both long-term biphasic pulse stimulation and aggressive cyclic voltammetric stimulation, and great biocompatibility in vitro. Supronowicz et al. reported the 740 application of nanocomposites consisting of polylactic acid and CNT blends on cell electrical stimulation [188]. Chao et al. prepared a 2D thin film scaffold composed of biocompatible polymer [poly(acrylic acid)] grafted carbon nanotubes (CNTs), which can selectively differentiate 745 human embryonic stem cells into neuron cells while maintaining excellent cell viability [189]. Neuron differentiation efficiency of poly(acrylic acid) grafted CNT thin films was significantly greater than that on poly(acrylic acid) thin films. The surface analysis and cell 750 adhesion study have suggested that CNT-based surfaces can enhance protein adsorption and cell attachment. This finding indicates that CNT-based materials are excellent candidates for hESCs' neuron differentiation. 


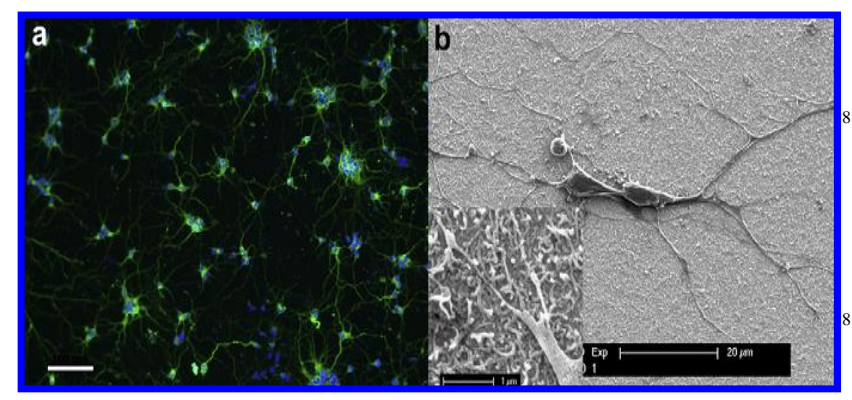

Figure 9. Fluorescent (a) and SEM (b) images of neurons ${ }_{760}$ cultured on PEDOT/CNT surfaces. For the fluorescent image, the scale bar represents $100 \mathrm{~mm}$. The inset in (b) shows the SEM of neurites grown on the PEDOT/CNT surface with high magnification.

765 Recently, Nguyen-Vu and colleagues fabricated a vertically aligned carbon nanofiber (VACNF) electrode coated with a thin film of conductive PPy for neural implants [190, 191]. The nanoelectrode array had more open and strong 3D structures, and better electrical 770 conductivity. The study showed that the vertical CNF arrays helped to form an intimate neural-electrical interface between cells and nanofibers for neural prosthesis. McKenzie et al. investigated astrocyte (one of the glial scar tissue forming cells) function on CNFs/polycarbonate 775 urethane (PCU) composites [192]. They demonstrated for the first time that astrocyte adhesion could be effectively inhibited when incorporating and increasing the surface energy of CNFs in the polymer composites. Furthermore, CNFs could also support neuron growth and neurite 780 extension. Webster et al. described the cellular response of neuron and osteoblast cells to composites made up of CNFs as "fillers in polycarbonate urethane substrates". The cell response to the composite may result in successful integration of neural and bone tissue implants [193].

${ }_{785}$ Similarly, VACNFs coated with PPy by electrochemical deposition was also be used as for electrical stimulation [150]. CNFs, however,are easy to be bundled up, resulting in bigger, micron-sized fibers. For sucessful preparation of CNFs nanoarray, a conformal film of conducting polymers 790 (such as PPy) was deposited onto CNFs. The PPy coated CNFs were then coated by a thin layer of type IV collagen to improve biocompatibility of the CNFs. The cell growth rate on CNF arrays with the PPy and collagen coatings was dramatically increased compared to the "bare" CNF arrays ${ }_{795}$ or CNF arrays coated with PPy only. This improved biocompatibility of the functionalized VACNFs, along with their 3D nanostructure and superior electrical and mechanical property, make them suitable for neural applications such as functional electrical stimulation, deep 800 brain stimulation and neural prosthetics [148].

These studies suggeted that conducting polymer/carbon nanomaterials composite might provide extra advantages for the development of novel neural electrode based on conducting polymers or carbon nanomaterials, which are 805 able to offer a friendly interface bridging inorganic materials to a living body. Therefore, a comprehensive study on electrochemical characteristics and biocompatibility of these composites with concern to chronic implantable neural electrodes is required.

\section{Concluding Remarks and Future Perspective}

In the future, it is necessary to integrate neural-electrical interfaces and neural-chemical interfaces together for the development of intelligent, closed-loop therapeutic devices for diagnosis and treatment of neurological diseases, realizing automatic modulation of neural activity by neurostimulation or local drug delivery responding to real-time detection of electrical and chemical information 820 from the nervous system. The demand for developing therapies to neural disorders with strategies involving drug delivery, tissue repair, and electrical implants is urgent.

Nanoscale topological features have been shown to increase cell adhesion and viability which can be exploited 825 to make neuron-device coupling more reliable. Novel substrate coatings offered by nanomaterials can be used to immobilize cells and increase the number of cells growing neuritis. Manufacturing of this or similar devices, although technically possible, is limited by the physical properties of 830 the available materials. Recent work has focused on the feasibility of using high-capacitance, low resistance electrodes, with the goal of large scale integration with CNS interfaces. Many efforts have been made on developments of suitable materials includin conducting 835 polymers, carbon nanomaterials, composites and other potential materials. In this respect, studies on the chronic long-term toxicity of these materials over the period of implantation spanning several years are also necessary. In addition, nanomaterial-based scaffolds provide possiblity 840 to investigate the ability of multilayered nervous tissue in translating adhesive interactions into network activity in regions relatively far from the interface itself. These can, provide relevant information for the scientific community dealing with neuronal interfaces and electrodes even their 845 unique physicochemical properties pose potential risks to the health of humans.

The biosafety issues of carbon nanomaterials in practical applications are not clear yet. An increasing amount of evidence indicates that toxicity/pharmacodynamics of 850 carbon nanomaterials is critically influenced by the route of exposure/administration. Future developments of scaffolds/devices based on the carbon nanomaterials will therefore necessarilly take into account these issues. With the development of methodologies for the chemical 855 modification and functionalization of carbon nanomaterials, it opens up an even wider range of bioapplication opportunities, such as drug delivery, bioconjugation and specific recognition. The future design of carbon nanomaterial-based technologies will have to guarantee 860 their stability, full biocompatibility and safety. The unique properties of CNTs and the application of nanotechnology to the nervous system may have a tremendous impact on the future developments of micro systems for neural prosthetics as well as immediate benefits for basic research. 865 The utilization of CNFs in the nervous system, which have great potentials as multiplexing neural interfaces and 
intracellular neural interfaces, can provide high spatial resolution, high sensitivity, and minimal damage to neural tissue. Much attention still need to be paid for clinical 870 applications of CNTs, such as the biocompatibility of the materials introduced in the fabrication of $\mathrm{CNFs}$, the enhancement of homogeneity and yield of CNFs. Considering the well interactions between graphene and neurons, graphene can be used as implanted materials or 875 neural chips for the tissue engineering, especially in the nervous system. Despite of the challenges, for better understanding and better use of its biological effects, the graphene biocompatibility and interactions with an organism (tissue/cell) should be well clarified.

880 Incorporation of anti-inflammatory drugs in the coatings and neuronal guidance toward the electrode by selfassembled scaffolds represent the directions with greatest immediate and practical significance. The combination of neural guidance and drug elution capabilities in one 885 coating should be strongly considered. Future development of nanostructured coatings will also target significant increase of charge injection capacity and reduction of interface impedance. Nanoscale technology and/or coating with high aspect ratio features on the surface are known to 890 improve charge injection in neurons.

The incorporation of light-sensitive materials in neural electrodes is another promising direction for the future development. The presence of photoreactions at the interface gives additional restrictions on the materials to be 895 used such as their biocompatibility, and long-term stability. More stable inorganic semiconductor materials that are active in the visible spectrum tend to contain heavy metals, which are likely to cause problems with long-term biocompatibility. Hence developments of alternate 900 nanostructured materials and potentially differently doped inorganic nanocolloids should be charted as one of the future tasks in this area. For an instance, fullerene coatings can serve as an intermediate solution for this offering both strong photovoltaic activity in the visible range and radical 905 savaging. CNTs may also give adequate performance and can possibly surpass other materials as a potential candidate for an artificial retina.

\section{ACKNOWLEDGEMENT}

Financial supports from the Chinese National Nature Science Foundation (21374081), the Wenzhou Technological Project (S20130001), the Ministry of Education of China (211069, SRF for ROCS), the Zhejiang ${ }_{915}$ Department of Education (T200917), and Zhejiang National Nature Science Foundation (Y13H180013) are 97. acknowledged.

920

\section{REFERENCES}

[1] Zhang, N.; Yan, H.; Wen, X. Tissue-engineering approaches for axonal guidance. Brain Res. Rev. 2005, 49, 48-64.

925 [2] Tresco PA. Tissue engineering strategies for nervous system repair; In: Progress in brain research. Seil, F.J. (Ed.), New York: Elsevier Science B.V.; 2000, 349363.

[3] Woerly, S., Plant, G.W.; Harvery, A.R. Neural tissue engineering: from polymer to biohybrid organs. Biomaterials 1996, 17, 301-310.

[4] Gregory, R.D.E. Peripheral nerve injury: a review and approach to tissue engineered constructs. Anatom. Rec. 2001, 263, 396-404.

${ }_{935}$ [5] Millesi, H. Indications and techniques of nerve grafting. In: Operative Nerve Repair and Reconstruction; Gelbertman, R.H., Lippincott, J.B., Eds, Philadelphia, 1991, 525-544.

[6] Terzis, J.K.; Sun, D.D.; Thanos, P.K. Historical and basic science review: past, present, and future of nerve repair. J. Reconstr. Microsurg. 1997, 13, 215225.

[7] James, R.B. Peripheral nerve and neuromuscular allotransplantation: current status. Microsurgery, 2000, 20, 384-388.

[8] Zalewski, A.A.; Gulati, A.K. Rejection of nerve allografts after cessation of immunosuppression with cyclosporin A. Transplantation, 1981, 31, 88-89.

[9] Tran, P.A.; Zhang, L.; Webster, T.J. Carbon nanofibers and carbon nanotubes in regenerative medicine. Advanced Drug Delivery Reviews, 2009, 61, 1097-1114.

[10] Shi, G.; Zhang, Z.; and Rouabhia, M. The regulation of cell functions electrically using biodegradable polypyrrole-polylactide conductors. Biomaterials, 2003, 9, 3792-3798.

[11] Vodovnik, L.; Miklavcic, D.; Sersa, G. Modified cell proliferation due to electrical currents, Cellular Engineering: Medical \& Biological Engineering \& Computing, 1992, 30 (4), 21-28.

[12] Altschuler, R.A.; Cho, Y.; Ylikoski, J.; Pirvola, U.; Magal, E.; Miller, J.M. Rescue and Regrowth of Sensory Nerves Following Differentiation by Neurotrophic Factors. In: Ototoxicity Basic Science and Clinical Applications, Henderson, Salvi, Quaranta, McFadden and Burkard, Eds. The New York Academy of Sciences, New York, 1999.

[13] Du, J.; Feng, L.; Yang, F.; Lu, B. Activity- and $\mathrm{Ca}(2+)$-dependent modulation of surface expression of brain-derived neurotrophic factor receptors in hippocampal neurons. J. Cell Biol., 2000, 150, 14231434.

[14] Ghasemi-Mobarakeh, L.; Prabhakaran, M.P.; Morshed, M.; Nasr-Esfahani, M.H.; Ramakrishna, S. Electrical Stimulation of Nerve Cells Using Conductive Nanofibrous Scaffolds for Nerve Tissue Engineering. Tissue Eng. Part A, 2009,15, 3605-3619.

[15] Oh, M.Y.; Hodaie, M.; Kim, S.H.; Alkhani, A.; Lang, A.E.; Lozano, A.M. Deep brain stimulator electrodes used for lesioning: proof of principle. Neurosurgery, 2001, 49, 363-7.

[16] Okun, M.S.; Rodriguez, R.L.; Foote, K.D.; Sudhyadhom, A.; Bova, F.; Jacobson, C.; Bello, B.; Zeinman, P.; Fernandez, H.H. A case-based review of 
troubleshooting deep brain stimulator issues in movement and neuropsychiatric disorders. Parkinsonism Relat D, 2008, 14, 532-8.

[17] Sparreboom, M.; van Schoonhoven, J.; van Zanten, B.G.; Scholten, R.J.; Mylanus, E.A.; Grolman, W., Maat, A. The effectiveness of bilateral cochlear implants for severe-to-profound deafness in children: a systematic review. Otol. Neurotol., 2010, 31, 10621071.

[18] Johnston, J.C.; Durieux-Smith, A.; Angus, D.; O'Connor, A.; Fitzpatrick, E. Bilateral paediatric cochlear implants: a critical review. Int. J. Audiol. 2009, 48, 601-617.

[19] Waltzman, S.B. Cochlear implants: current status. Expert. Rev. Med. Devic. 2006, 3, 647-655.

1000 [20] Zhou, D.D. Greenberg R. Microelectronic visual prostheses. In: Zhou David, Greenbaum Elias, editors. Implantable neural prostheses 1, devices and applications, biological and medical physics, biomedical engineering. Springer, 2009. 1-42.

1005 [21] Theodore, W.H.; Fisher, R.S. Brain stimulation for epilepsy. Lancet Neurol. 2004, 3,111-118.

[22] Mayberg, H.S.; Lozano, A.M.; Voon, V.; McNeely, H.E.; Seminowicz, D.; Hamani, C.; Schwalb, J.M., Kennedy, S.K. Deep brain stimulation for treatment1010 resistant depression. Neuron, 2005, 45, 651-60.

[23] Falowski, S.; Celii, A.; Sharan, A. Spinal cord stimulation: an update. Neurotherapeutics, 2008, 5, 86-99.

[24] Collazos-Castro, J.E.; Muñetón-Gómez, V.; Nieto-

1015 Sampedro, M. Olfactory glia transplantation into cervical spinal cord contusion injuries. J. Neurosurg 1075 Spine, 2005, 3, 308-317.

[25] Goldberg, J.L.; Espinosa, J.S.; Xu, Y.; Davidson, N.; Kovacs, G.T.; Barres, B.A. Retinal ganglion cells do

1020 not extend axons by default: promotion by neurotrophic signaling and electrical activity. Neuron, 2002, 33, 689-702.

[26] McCaig, C.D.; Rajnicek, A.M.; Song, B.; Zhao, M. Controlling cell behavior electrically: current views 1025 and future potential. Physiol. Rev.,2005, 85, 943-78.

[27] Merrill, D.R.; Bikson, M.; Jefferys, J.G.R. Electrical 1085 stimulation of excitable tissue: design of efficacious and safe protocols. J. Neurosci. Methods, 2005, 141, 171-198.

1030 [28] Rose, T.L.; Robblee, L.S. Electrical-stimulation with $\mathrm{Pt}$ electrodes. VIII. Electrochemically safe charge injection limits with $0.2 \mathrm{~ms}$ pulses. IEEE Trans. Biomed. Eng., 1990, 37, 1118-20.

[29] Meyer, R.D.; Cogan, S.E.; Nguyen, T.H.; Rauh, R.D. 1035 Electrodeposited iridium oxide for neural stimulation and recording electrodes. IEEE T. Neur. Sys. Reh., 2001, 9, 2-11.

[30] Weiland, J.D.; Anderson, D.J. Chronic neural stimulation with thin-film, iridium oxide electrodes.

1040 IEEE T. Bio-Med Eng., 2000, 47, 911-918.

[31] Niebauer, M.J.; Wilkoff, B.; Yamanouchi, Y.; Mazgalev, T.; Mowrey, K.; Tchou, P. Iridium oxidecoated defibrillation electrode e reduced shock polarization and improved defibrillation efficacy. Circulation, 1997, 96, 3732-3736.

[32] Negi, S.; Bhandari, R.; Rieth, L.; Solzbacher, F. In vitro comparison of sputtered iridium oxide and platinum-coated neural implantable microelectrode arrays. Biomed. Mater., 2010, 5, 015007.

1050 [33] Cogan, S.F.; Guzelian, A.A.; Agnew, W.F.; Yuen, T.G.; McCreery, D.B. Over-pulsing degrades activated iridium oxide films used for intracortical neural stimulation. J. Neurosci. Methods, 2004, 137, 141-150.

1055 [34] Mailley, S.C.; Hyland, M.; Mailley, P.; McLaughlin, J.M.; McAdams, E.T. Electrochemical and structural characterizations of electrodeposited iridium oxide thin-film electrodes applied to neuro stimulating electrical signal. Mat. Sci. Eng. C-Bio. S. , 2002, 21, 167-175.

[35] Abidian, M.R.; Kim, D.H.; Martin, D.C. Conductingpolymer nanotubes for controlled drug release. $A d v$. Mater., 2006, 18, 405-409.

[36] Tasis, D.; Tagmatarchis, N.; Bianco, A.; Prato, M. Chemistry of carbon nanotubes. Chem. Rev., 2006, 106, 1105-1136.

[37] Gangopadhyay, R., De, A. Conducting polymer nanocomposites: a brief overview. Chem. Mater., 2000, 12, 608-622.

1070 [38] MacDiarmid, A.G. Nobel lecture: "synthetic metals"': a novel role for organic polymers. Rev. Mod. Phys., 2001, 73, 701-12.

[39] Pedrotty, D.M.; Koh, J.; Davis, B.H.; Taylor, D.A.; Wolf, P.; Niklason, L.E. Engineering skeletal myoblasts: roles of three-dimensional culture and electrical stimulation. Am. J. Physiol. Heart. Circ. Physiol., 2005, 288, H1620-1626.

[40] Wong, J.Y.; Langer, R. and Ingberi, D.E. Electrically conducting polymers can noninvasively control the shape and growth of mammalian cells. Proc. Natl. Acad. Sci., USA, 1994, 91, 3201.

[41] Kim, D.H.; Richardson-Burns, S.M.; Hendricks, J.L.; Sequera, C.; Martin, D.C. Effect of immobilized nerve growth factor on conductive polymers: electrical properties and cellular response. Adv. Funct. Mater., 2007, 17, 79-86.

[42] Cui, X.Y.; Wiler, J.; Dzaman, M.; Altschuler, R.A.; Martin, D.C. In vivo studies of polypyrrole/peptide coated neural probes. Biomaterials, 2003, 24, 777-87.

1090 [43] Kim, K.; Yu, M.; Zong, X.; Chiu, J. ; Fang, D. ; Seo, Y.S.; Hsiao, B.S.; Chu, B; Hadjiargyrou, M. Control of degradation rate and hydrophilicity in electrospun non-woven poly(D,L-lactide) nanofiber scaffolds for biomedical applications. Biomaterials, 2003, 24, 4977-4985.

[44] Zong, X.; Bien, H. ; Chung, C.Y. ; Yin, L. ; Fang, D. ; Hsiao, B.S. ; Entcheva, E. "Electrospun fine-textured scaffolds for heart tissue constructs", Biomaterials, 2005, 26, 5330-5338.

1100 [45] Metzke, M.; O’Connor, N.; Maiti, S.; Nelson, E.; Guan, Z. Saccharidepeptide hybrid copolymers as biomaterials. Angew. Chem. Int. Ed. Engl., 2005, 
44(40), 6529-6533.

[46] Boland, E.D.; Matthews, J.A.; Pawlowski, K.J.; ${ }_{1105}$ Simpson, D.G.; Wnek, G.E.; Bowlin, G.L. Electrospinning collagen and elastin: preliminary 1165 vascular tissue engineering. Front Biosci., 2004, 9, $1422-1432$.

[47] Li, M.; Mondrinos, M.J.; Gandhi, M.R.; Ko, F.K.; 1110 Weiss, A.S.; Lelkes, P.I. Electrospun protein fibers as matrices for tissue engineering. Biomaterials 2005, 26(30), 5999-6008.

[48] Rho, K.S.; Jeong, L.; Lee, G.; Seo, B.M.; Park, Y.J.; Hong, S.D.; Roh, S.; Cho J.J.; Park, W.H.; Min, B.M. 1115 Electrospinning of collagen nanofibers: Effects on the behavior of normal human keratinocytes and early stage wound healing. Biomaterials, 2006, 27, 1452.

[49] Riboldi, S.A.; Sampaolesi, M.; Neuenschwander, P.; Cossu, G.; Mantero, S. Electrospun degradable

1120 polyesterurethane membranes: potential scaffolds for skeletal muscle tissue engineering. Biomaterials, 2005, 1180 26(22), 4606-4015.

[50] Ma, Z.; Kotaki, M.; Inai, R.; Ramakrishna, S. Potential of nanofiber matrix as tissue-engineering scaffolds. Tissue Eng., 2005, 11(1-2), 101-109.

[51] Yang, F.; Murugan, R.; Wang, S.; Ramakrishna, S. Electrospinning of nano/micro scale poly(L-lactic acid) aligned fibers and their potential in neural tissue engineering. Biomaterials, 2005, 26(15), 2603-2610.

${ }_{1130}$ [52] Khil, M.S.; Bhattarai, S.R.; Kim, H.Y.; Kim, S.Z.; Lee, K.H. Novel fabricated matrix via electrospinning for tissue engineering. J. Biomed. Mater. Res. B Appl. Biomater., 2005, 72(1), 117-24.

[53] Khil, M.S.; Cha, D.I.; Kim, H.Y.; Kim, I.S.; Bhattarai, $\mathrm{N}$. Electrospun nanofibrous polyurethane membrane as wound dressing. J. Biomed, Mater. Res. B Appl. Biomater., 2003, 67(2), 675-679.

[54] Zeng, J.; Yang, L. ; Liang, Q. ; Zhang, X. ; Guan, H. ; $\mathrm{Xu}, \mathrm{X}$.; Chen, $\mathrm{X}$. ; Jing, $\mathrm{X}$. Influence of the drug

1140 compatibility with polymer solution on the release kinetics of electrospun fiber formulation. J. Control. Release, 2005, 105(1-2), 43-51.

[55] Buttafoco, L.; Kolkman, N.G.; Poot, A.A.; Dijkstra, P.J.; Vermes, I.; Feijen, J. Electrospinning collagen and elastin for tissue engineering small diameter blood vessels. J. Control. Release, 2005, 101(1-3), 1205 322-324.

[56] Guimard, N.K.; Gomez, N. Schmidt CE. Conducting polymers in biomedical engineering. Prog. Polym.

1150 Sci., 2007, 32, 876-921.

[57] Shi, G.; Rouabhi, M.; Wang, Z.; Dao, L.; Zhang, Z. A novel electrically conductive and biodegradable composite made of polypyrrole nanoparticles and polylactide. Biomaterials, 2004, 25, 2477-2488.

1155 [58] Bhat, N.V.; Shaikh, Y.B. Synthesis and structure investigation of conductive composites from 1215 cellophane and polypyrrole. J. Appl. Polym. Sci., 1994, 53, 187-191.

[59] Kaynak, A.; Unsowrth, J.; Clout, R.; Mohan, A.S.; Bears, G.E. A study of microwave transmission, reflection, absorption, and shielding effectiveness of ${ }_{1220}$ conductive polypyrrole films. J. Appl. Polym. Sci., 1994, 54, 269-278.

[60] Jager, E.W.H.; Smela, E.; Inganas, O. Microfabricating conjugated polymer actuators. Science, 2000, 290, 1540-1545.

[61] Mermilliod, N.; Tanguy, J. A study of chemically synthesized polypyrrole as electrode material for battery applications. J. Electrochem. Soc., 1986, 133, 1073-1079.

[62] Cen, L.; Neoh, K.G.; Kang, E.T. Surface functionalization of polypyrrole film with glucose oxidase and viologen. Biosens. Bioelectron., 2003, 18, 363-374.

1175 [63] Lopez-Crapez, E.; Livache, T.; Marchand, J.; Grenier, J. K-ras mutation detection by hybridization to a polypyrrole DNA chip. Clin. Chem., 2001, 47, 186194.

[64] Schmidt, C.E.; Shastri, V.R.; Vacanti, J.P.; Langer, R. Stimulation of neurite outgrowth using an electrically conductive polymer. Proc. Nat. Acad. Sci., 1997, 94, 8948-8953.

[65] Williams, R.L.; Doherty, P.J. Preliminary assessment of poly(pyrrole) in nerve guide studies. J. Mater. Sci., 1994, 5, 429-433.

[66] Aoki, T.; Tanino, M.; Ogata, N.; Kumakura, K. Secretory function of adrenal chromaffin cells cultured on polypyrrole films. Biomaterials, 1996, 17, 1971-1974.

190 [67] Garner, B.; Georgevich, A.; Hodgson, A.J.; Liu, L.; Wallace, G.G. Polypyrrole-heparin composites as stimulus-responsive substrates for endothelial cell growth. J. Biomed. Mater. Res., 1999, 44, 121-129.

[68] Kotwal, A.; Schmidt, C.E. Electrical stimulation alters protein adsorption and nerve cell interactions with electrically conducting biomaterials. Biomaterials, 2001, 22, 1055-1064.

[69] Sanghvi, A.B.; Miller, K.P.; Belcher, A.M.; Schmidt, C.E. Biomaterials functionalization using a novel peptide that selectively binds to a conducting polymer. Nat. Mater., 2005, 4(6), 496-502.

[70] Lakard, S.; Herlem, G.; Valles-Villareal, N.; Michel, G.; Propper, A.; Gharbi, T.; Fahys, B. Culture of neural cells on polymers coated surfaces for biosensor applications. Biosens. Bioelectron., 2005, 20(10), 1946-1954.

[71] George, P.M.; Lyckman, A.W.; LaVan, D.A.; Hegde, A.; Leung, Y.; Avasare, R.; Testa, C.; Alanxander, P.M., Langer, R.; Sur, M. Fabrication and biocompatibility of polypyrrole implants suitable for neural prosthetics. Biomaterials, 2005, 26(17), 35113219.

[72] Wan, Y.; Wu, H.; Wen, D. Porous-conductive chitosan scaffolds for tissue engineering, 1. Preparation and characterization. Macromol. Biosci., 2004, 4(9), 882-890.

[73] Jiang, X. ; Marois, Y. ; Traore, A. ; Tessier, D.; Dao, L.H.; Guidoin, R.; Zhang, Z. Tissue reaction to polypyrrole-coated polyester fabrics: an in vivo study in rats. Tissue Eng. 2002, 8(4), 635-647. 
[74] Liu, Y.; Liu, X.; Chen, J.; Gilmore, K.J.; Wallace, G.G. 3D Bio-nanofibrous $\mathrm{PPy}=\mathrm{SIBS}$ mats as platforms for cell culturing. Chem. Commun., 2008, 32, 372.

${ }_{1225}$ [75] Runge, M.B.; Dadsetan, M.; Baltrusaitis, J.; Knight, A.M.; Ruesink, T.; Lazcano, E.A.; Lu, L.; Windebank, 1285 A.J.; Yaszemski, M.J. The development of electrically conductive polycaprolactone fumarate- polypyrrole composite materials for nerve regeneration. Biomaterials, 2010, 31, 5916-5926.

[76] Omastova, M.; Pavlinec, J.; Pionteck, J.; Simon, F.; 1290 Kosina, S. Chemical preparation and characterization of conductive poly(-methyl methacrylate)/polypyrrole composites. Polymer, 1998, 39, 6559-6566.

${ }_{1235}$ [77] Nikpour, M.; Chaouk, H.; Mau, A.; Chung, D.J.; Wallace, G. Porous conductive films based on polypyrrole-PMMA composites. Synth. Met., 1999, 99, 121-126.

[78] Nakata, M.; Kise, H. Preparation of polypyrrole-

1240 poly(vinylchloride) composite films by interphase oxidative polymerization. Polym. J. (Tokyo, Japan) 1300 1993, 25, 91-94.

[79] Cairns, D.B.; Armes, S.P.; Bremer, L.G.B. Synthesis and characterization of submicrometer-sized 1245 polypyrrole-polystyrene composite particles. Langmuir, 1999, 15, 8052-8058.

[80] He, F.; Omoto, M.; Yamamoto, T.; Kise, H Preparation of polypyrrole-polyurethane composite foam by vapour phase oxidative polymerization. $J$.

$1250 \quad$ Appl. Polym. Sci., 1995, 55, 283-287.

[81] Freed, L.E.; Vunjak, N.G.; Biron, R.J.; Eagles, D.B.; Lesnoy, D.C.; Barlow, S.K.; Langer, R. Biodegradable polymer scaffolds for tissue engineering. Biotechniques, 1994, 12, 689-693.

${ }_{1255}$ [82] Mikos, A.G.; Bao, Y.; Cima, L.G.; Ingber, D.E.; Vacanti, J.P.; Langer, R. Preparation of poly(glycolic acid) bonded fibre structure for cell attachment and transplantation. J. Biomed. Mater. Res. 1993, 27, 183-189.

1260 [83] Daniels, A.U.; Chang, M.K.O.; Andriano, K.P. Mechanical properties of biodegradable polymers and composites proposed for internal fixation of bone. $J$. Appl. Biomater., 1990, 1, 57-58.

[84] Widmer, M.S.; Gupta, P.K.; Lu, L.; Meszlenyi, R.K.;

1265 Evans, G.R.; Brandt, K.; Savel, T.; Gurlek, A.; Patrick, Jr C.W.; Mikos, A.G. Manufacture of porous biodegradable polymer conduit by an extrusion process for guided tissue engineering. Biomaterials, 1998, 19, 1945-1955.

1270 [85] Den Dunnen, W.F.A.; Schakenraad, J.M.; Zondervan, G.J.; Pennings, A.J.; van der Lei, B.; Robinson, P.H. A new PLLA/PCL copolymer for nerve regeneration. J. Mater. Sci. Mater. Med., 1993, 4: 521-525.

[86] Durgam, H.; Sapp, S.; Deister, C.; Khaing, Z.; Chang, $1275 \quad$ E.; Luebben, S.; Schmidt, C.E. Novel Degradable copolymers of polypyrrole support cell proliferation and enhance neurite out-growth with electrical stimulation. J. Biomater. Sci. Polym. Ed., 2010, 21, $1265-1282$.
1280 [87] Bao, Y.; Cima, L.G.; Ingber, D.E.; Vacanti, J.P.; Langer, R. Preparation of poly(glycolic acid) bonded fibre structure for cell attachment and transplantation. J. Biomed. Mater. Res., 1993, 27, 183-189.

[88] Huang, J.; Hu, X.; Lu, L.; Ye, Z.; Zhang, Q.; Luo, Z. Electrical regulation of Schwann cells using conductive polypyrrole/chitosan polymers. J. Biomed. Mater. Res. Part A, 2010, 93, 164-174.

[89] Moroder P.; Runge M.B.; Wang, H.; Ruesink, T.; Lu, L.; Spinner, R.J.; Windebank, A.J.; Yaszemski, M.J. Material properties and electrical stimulation regimens of polycaprolactone fumarate-polypyrrole scaffolds as potential conductive nerve conduits. Acta Biomaterialia , 2011, 7, 944-953.

[90] Bai, X.; Li, X.; Li, N.; Zuo, Y.; Wang, L.; Li, J.; Qiu, $\mathrm{S}$. Synthesis of cluster polyaniline nanorod via a binary oxidant system. Mater. Sci. Eng. C, 2007, 27, 695-699

[91] Li, M.Y.; Guo, Y.; Wei, Y.; MacDiarmid, A.G.; Lelkes, P.I. Electrospinning polyaniline contained gelatin nanofibers for tissue engineering applications. Biomaterials, 2006, 27, 2705-2715.

[92] Ahmad N, MacDiarmid AG. "Inhibition of corrosion of steels with the exploitation of conducting polymers". Synth. Met., 1996, 78, 103-110.

${ }_{1305}$ [93] Yang, Y.; Westerweele, E.; Zhang, C.; Smith, P.; Heeger, A.J. Enhanced performance of polymer lightemitting diodes using high-surface area polyaniline network electrodes. J. Appl. Phys., 1995, 77, 694698.

1310 [94] MacDiarmid, A.G.; Yang, L.S.; Huang, W.S.; Humphrey, B.D. Polyaniline: electrochemistry and application to rechargeable batteries. Synth. Met., 1987, 18, 393-398.

[95] Bidez, P.R.; Li, S.; Macdiarmid, A.G.; Venancio, E.C.; Wei, Y.; Lelkes, P.I. Polyaniline, an electroactive polymer, supports adhesion and proliferation of cardiac myoblasts. J. Biomater. Sci. Polym. Ed., 2006, 17.

[96] Li, D.F.; Wang, W.; Wang, H.J.; Jia, X.S.; Wang, J.Y. Polyaniline films with nanostructure used as neural probe coating surfaces. Appl. Surface Sci., 2008, 255, 581.

[97] Guimarda, N.K.; Gomezb, N.; Schmidt, C.E. Conducting polymers in biomedical engineering. Prog. Polym. Sci., 2007, 32, 876.

[98] Kamalesh, S.; Tan, P.; Wang, J.; Lee, T.; Kang, E.T.; Wang, C.H. Biocompatibility of electroactive polymers in tissues. J. Biomed. Mater. Res., 2000, 52, 467.

330 [99] Mattioli-Belmonte, M.; Giavaresi, G.; Biagini, G.; Virgili, L.; Giacomini, M.; Fini, M.; Giantomassi, F.; Natali, D.; Torricelli, P.; Giardino, R. Tailoring biomaterial compatibility: in vivo tissue response versus in vitro cell behavior. Int. J. Artif. Organs., 2003, 26, 1077.

[100] Schmidt, C.E.; Shastri, V.R.; Vacanti, J.P.; Langer, R. Stimulation of neurite outgrowth using an electrically conducting polymer. Proc. Natl. Acad. Sci. 
USA, 1997, 94, 8948.

1340 [101] Sun, S.; Titushkin, I.; Cho, M. Regulation of mesenchymal stem cell adhesion and orientation in 3D collagen scaffold by electrical stimulus. Bioelectrochemistry, 2006, 69, 133.

[102] Shi, G.; Rouabhia, M.; Meng, S.; Zhang, Z. 1345 Electrical stimulation enhances viability of human cutaneous fibroblasts on conductive biodegradable substrates. J. Biomed. Mater. Res. Part A, 2007, 84A, 1026 ,

[103] Li, M.; Guo, Y.; Wei, Y.; MacDiarmid, A.G.; ${ }_{1350} \quad$ Lelkes, P.I. "Electrospinning polyaniline-contained gelatin nanofibers for tissue engineering applications. Biomaterials, 2006, 27, 2705.

[104] Li, M.; Guo, Y.; Wei, Y.; MacDiarmid, A.G.; Lelkes, P.I. "Electrospinning polyaniline-contained gelatin nanofibers for tissue engineering applications", Biomaterials, 2006, 27, 2705-2715.

[105] Jeong, S.I.; Jun, I.D.; Choi, M.J.; Nho, Y.C.; Lee, Y.M.; Shin, H. Development of electroactive and elastic nanofibers that contain polyaniline and poly

1360 (L-lactide-co-e-caprolactone) for the control of cell adhesion. Macromol. Biosci., 2008, 8, 627.

[106] Ghasemi-Mobarakeh, L.; Prabhakaran, M.P.; Morshed, M.; Nasr-Esfahani, M. H.; Ramakrishna, S. Electrical Stimulation of Nerve Cells Using

1365 Conductive Nanofibrous Scaffolds for Nerve Tissue Engineering. Tissue Engineering: Part A, 2009, 15, 3605-3619.

[107] Lin, T.H.; Ho, K.C. Acomplementary electrochromic device based on polyani- line and poly $(3,4$

1370 ethylenedioxythiophene), Sol. Energy Mater. Sol. Cells, 2006, 90, 506-520.

[108] Ko, H.C.; Kim, S.; Lee, H.; Moon, B. Multicolored electrochromism of a poly $\{1,4-$ bis $[2-(3,4-$ ethylenedioxy) thienyl] benzene \} derivative bearing viologen functional groups, Adv. Funct. Mater., 2005, $15,905-909$.

[109] Argun, A.A.; Cirpan, A.; Reynolds, J.R. The first truly all-polymer electrochromic devices, $A d v$. Mater., 2003, 15, 1338

1380 [110] Groenendaal, B.L.; Jonas, F.; Freitag , D.; Pielartzik, H.; Reynolds, J.R. Poly(3,4-ethylenedioxythiophene) and its derivatives: past, present, and future. $A d v$. Mater. 2000, 12, 481-494.

[111] Cui, X.T.; Zhou, D.D. Poly (3,4-ethylene-dioxythiophene) for Chronic Neural Stimulation. IEEE Trans. Neural Syst. Rehabil. Eng., 2007, 15 (4), 502508.

[112] Cui, X.Y.; Martin, D.C. Electrochemical Deposition and Characterization of Poly (3, 41390 ethylenedioxythiophene) on Neural Microelectrode Arrays. Sens. Actuators B, 2003, 89, 92-102.

[113] Hendricks, J.L.; Chikar, J.A.; Crumling, M.A.; Raphael, Y.; Martin, D.C. Localized cell and drug delivery for auditory prostheses. Hear. Res., 2008, $1395 \quad 242(1-2), 117-131$.

[114] Jan, E.; Hendricks, J.L.; Husaini, V.; RichardsonBurns, S.M.; Sereno, A.; Martin, D.C.; Kotov, N.A.
Layered carbon nanotube-polyelectrolyte electrodes outperform traditional neural interface materials. Nano Lett., 2009, 9, 4012-4018.

[115] Bolin, M.H.; Svennersten, K.; Wang, X.; Chronakis, I.S.; Richter-Dahlfors, A.; Jager, E.W.H.; Berggren, M. Nano-fiber scaffold electrodes based on PEDOT for cell stimulation. Sensors and Actuators B, 2009, $142,451-456$.

[116] Collazos-Castro, J.E.; Polo, J.L.; HernándezLabrado, G.R.; Padial-Cañete, V.; García-Rama, C. Bioelectrochemical control of neural cell development on conducting polymers. Biomaterials, 2010, 31, 9244-9255.

[117] Widmer, M.S.; Gupta, P.K.; Lu, L.; Meszlenyi, R.K.; Evans, G.R.D.; Brandt, K.; Savel, T.; Gukrlek, A.; Patrick, C.W.; Mikos, A.G. Manufacture of porous biodegradable polymer conduits by an extrusion process for guided tissue regeneration. Biomaterials, 1998, 19, 1945-1955.

[118] Rangappa, N.; Romero, A.; Nelson, K.D.; Eberhart, R.C. Smith, G.M. Laminin-coated poly(L-lactide) filaments induce robust neurite growth while providing directional orientation, J. Biomed. Mater. Res., 2000, 51, 625-634.

[119] Yang, F.; Murugan, R.; Ramakrishna, S.; Wang, X.; Ma, Y.-X.; Wang, S. Fabrication of nano-structured porous PLLA scaffold intended for nerve tissue engineering, Biomaterials, 2004, 25, 1891-1900.

[120] Prabhakaran, M.P.; Ghasemi-Mobarakeh, L.; Jin, G.; Ramakrishna, S. Electrospun conducting polymer nanofibers and electrical stimulation of nerve stem cells, Journal of Bioscience and Bioengineering., 2011, 112 (5), 501-507,

[121] Bekyarova, E.; Ni, Y.; Malarkey, E.B.; Montana, V.; McWilliams, J.L.; Haddon, R.C.; Parpura, V. Applications of Carbon Nanotubes in Biotechnology and Biomedicine. J. Biomed. Nanotech., 2005, 1, 317.

[122] Wang, J. Carbon-Nanotube Based Electrochemical Biosensors: A Review. Electroanalysis, 2005, 17, 714.

[123] Yun, Y.; Dong, Z.; Shanov, V.; Heineman, W.R.; Halsall, H.B.; Bhattacharya, A.; Conforti, L.; Narayan, R.K.; Ball, W.S.; Schulz, M.J. Nano Today, 2007, 2, 30.

[124] Rivas, G.A.; Rubianes, M.D.; Rodrı 'guez, M.C.; Ferreyra, N.F.; Luque, G.L.; Pedano, M.L.; Miscoria, S.A.; Parrado, C. Talanta, 2007, 74, 291.

[125] Baughman, R.H.; Cui, C.; Zakhidov, A.A.; Iqbal, Z.; Barisci, J.N.; Spinks, G.M.; Wallace, G.G.; Mazzoldi, A.; Rossi, D.D.; Rinzler, A.G.; Jaschinski, O.; Roth, S.; Kertesz, M. Carbon Nanotube Actuators. Science, 1999, 284, 1340.

[126] Fennimore, A.M.; Yuzvinsky, T.D.; Han, W.-Q.; Fuhrer, M.S.; Cumings, J.; Zettl, A. Rotational actuators based on carbon nanotubes. Nature, 2003, 424, 408.

[127] Kam, N.W.S.; O’Connell, M.; Wisdom, J.A.; Dai, $\mathrm{H}$. Carbon nanotubes as multifunctional biological 
transporters and near-infrared agents for selective cancer cell destruction. Proc. Natl. Acad. Sci. USA, 2005, 102, 11600.

1460 [128] Mattson, M.P.; Haddon, R.C.; Rao, A.M. Molecular functionalization of carbon nanotubes and use as substrates for neuronal growth. J. Mol. Neurosci. 2000, 14, 175-182.

[129] Tran, P.A.; Zhang, L.; Webster, T.J.; Carbon nanofibers and carbon nanotubes in regenerative medicine. Advanced Drug Delivery Reviews, 2009, 61, 1097-1114.

[130] Lu, F.; Gu, L.; Meziani, M.J.; Wang, X.; Luo, P.G.; Veca, L.M.; Cao, L.; Sun, Y. Advances in 1470 Bioapplications of Carbon Nanotubes. Adv. Mater. 2009, 21, 139-152.

[131] Mattson, M.P.; Haddon, R.C.; Rao, A.M. Molecular Functionalization of Carbon Nanotubes and Use as Substrates for Neuronal Growth, Journal of Molecular Neuroscience, 2000, 14, 175-182.

[132] Hu, H.; Ni, Y.; Montana, V.; Haddon, R.C.; Parpura, V. Chemically functionalized carbon nanotubes as substrates for neuronal growth. Nano Lett.., 2004, 4, 507-511.

1480 [133] Gabay, T.; Jakobs, E.; Ben-Jakob, E.; Hanein, Y. Engineered self-organization of neural networks using carbon nanotube clusters. Physica. A, 2005, 350, 611-21

[134] Anava, S.; Greenbaum, A.; Ben-Jacob, E.; Hanein,

1485 Y.; Ayali, A. The regulative role of neurite mechanical tension in network development, Biophys. J., 2009, 96: 1661-1670.

[135] Sorkin, R.; Greenbaum, A.; David-Pur, M.; Anava, S.; Ayali, A.; Ben-Jacob, E.; Hanein, Y. Process entanglement as a neuronal anchoragemechanismto rough surfaces. Nanotechnology, 2009, 20, 015101.

[136] Greenbaum, A.; Anava, S.; Ayali, A.; Shein, M.; David-Pur, M.; Ben-Jacob, E.; Hanein, Y. One-toone neuron-electrode interfacing. Journal of

1495 Neuroscience Methods, 2009, 182, 219-224.

[137] Lovat, V.; Pantarotto, D.; Lagostena, L.; Cacciari, B.; ${ }_{155}$ Grandolfo, M.; Righi, M.; Spalluto, G.; Prato, M.; Ballerini, L. Carbon nanotube substrates boost neuronal electrical signaling. Nano Lett., 2005, 5, 1107-1110.

[138] Cui, D.; Tian, F.; Ozkan, C.S.; Wang, M.; Gao, H. Effect of single wall carbon nanotubes on human HEK293 cells. Toxicol. Lett., 2005,155, 73-85

[139] Cellot, G.; Cilia1, E.; Cipollone, S.; Rancic, V.; Sucapane, A.; Giordani, S.; Gambazzi, L.; Markram, H.; Grandolfo, M.; Scaini, D.; Gelain, F.; Casalis, L.; Prato, M.; Giugliano, M.; Ballerini, L. Carbon nanotubes might improve neuronal performance by favouring electrical shortcuts. Nature Nanotech., 2009, 4, 126-133.

[140] Mazzatenta, A.; Giugliano, M.; Campidelli, S.; Gambazzi, L.; Businaro, L.; Markram, H.; Prato, M.; Ballerini, L. Interfacing Neurons with Carbon Nanotubes: Electrical Signal Transfer and Synaptic Stimulation in Cultured Brain Circuits. J. Neurosci.,
2007, 27(26), 6931-6936.

[141] Cellot, G.; Cilia, E.; Cipollone, S.; Rancic, V.; Sucapane, A.; Giordani, S.; Gambazzi, L.; Markram, H.; Grandolfo, M.; Scaini, D.; Gelain, F.; Casalis, L.; Prato, M.; Giugliano, M.; Ballerini, L. Carbon Nanotubes Might Improve Neuronal Performance by Favouring Electrical Shortcuts. Nat. Nanotechnol., 2009, 4, 126-133.

[142] Cellot, G.; Toma, F.M.; Varley, Z.K.; Laishram, J.; Villari, A.; Quintana, M.; Cipollone, S.; Prato, M.; Ballerini, L. Carbon Nanotube Scaffolds Tune Synaptic Strength in Cultured Neural Circuits: Novel Frontiers in Nanomaterial-Tissue Interactions. $J$. Neurosci., 2011, 3, 12945-12953.

1530 [143] Fabbro, A.; Villari, A.; Laishram, J.; Scaini, D.; Toma, F.M.; Turco, A.; Prato, M.; Ballerini, L. Spinal Cord Explants Use Carbon Nanotube Interfaces To Enhance Neurite Outgrowth and To Fortify Synaptic Inputs. ACS NANO, 2012, 6 (3), 2041-2055.

535 [144] Matsumoto, K.; Sato, C.; Naka,Y.; Whitby, R.; Shimizu, N. Stimulation of neuronal neurite outgrowth using functionalized carbon nanotubes. Nanotechnology, 2010, 21, 115101.

[145] Hu, H.; Ni, Y.; Montana, V.; Haddon, R. C.; Parpura, V. Chemically Functionalized Carbon Nanotubes as Substrates for Neuronal Growth. Nano Lett. 2004, 4, 507-511.

[146] Kam, N.W.S.; Jessop, T.C.; Wender, P.A.; Dai, H. Nanotube Molecular Transporters: Internalization of Carbon Nanotube-Protein Conjugates into Mammalian Cells. J. Am. Chem. Soc. 2004, 126, 6850-6851.

[147] Correa-Duarte, M.A.; Wagner, N.; Rojas-Chapana, J.; Morsczeck, C.; Thie, M.; Giersig, M. Fabrication and Biocompatibility of Carbon Nanotube-Based 3D Networks as Scaffolds for Cell Seeding and Growth. Nano Lett., 2004, 4, 11, 2233-2236.

[148] de Asis, E.D.; Nguyen-Vu, T.D.; Arumugam, P.U.; Chen, H.; Cassell, A.M.; Andrews, R.J.; Yang, C.Y.; Li, J. High efficient electrical stimulation of hippocampal slices with vertically aligned carbon nanofiber microbrush array. Biomedical Microdevices, 2009, 11(4), 801-808.

[149] Nguyen-Vu, T.D.; Chen, H.; Cassell, A.M.; Andrews, R.J.; Meyyappan, M.; Li, J. Vertically aligned carbon nanofiber architecture as a multifunctional 3-D neural electrical interface. IEEE Transactions on Biomedical Engineering, 2007, 54, 6, 1121-1128.

1565 [150] Nguyen-Vu, T.D.; Chen, H.; Cassell, A.M.; Andrews, R.; Meyyappan, M.; Li, J. Vertically Aligned Carbon Nanofiber Arrays: An Advance toward Electrical-Neural Interfaces. Small, 2006, 2(1), 89-94.

1570 [151] Yu, Z.; McKnight, T.E.; Ericson, M.N.; Melechko, A.V.; Simpson, M.L.; Morrison, B. Vertically aligned carbon nanofiber arrays record electrophysiological signals from hippocampal slices. Nano Lett., 2007, 
7(8), 2188-2195.

${ }_{1575}[152] \mathrm{Yu}, \mathrm{Z}$. Vertically aligned carbon nanofibre neural chip for interfacing with neurological system. Proceedings of the 2010 IEEE International Conference on Nano/Molecular Medicine and Engineering, 2010.

${ }_{1580}$ [153] Park, J.; Kwon, ,S.; Jun, S.L.; Mcknight, T.E.; Melechko, A.V.; Simpson, M.L.; Dhindsa, M.; Heikenfeld, J.; Rack, P.D. Active-Matrix Microelectrode Arrays Integrated With Vertically Aligned Carbon Nanofibers. Electron Device Letters, 1585 IEEE, 2009, 30(3), 254-257.

[154] McKnight, T.E.; Melechko, A.V.; Fletcher, B.L.; Jones, S.W.; Hensley, D.K.; Peckys, D.B.; Griffin, G.D.; Simpson, M.L.; Ericson, M.N. Resident neuroelectro-chemical interfacing using carbon nanofiber arrays. J. Phys. Chem. 2006, 110, 1531715327.

[155] Yu, Z.; .McKnight, T.E.; Ericson, M.N.; Melechko, A.V.; Simpson, M.L.; Morrison,B.; Vertically aligned carbon nanofiber arrays record electrophysiological signals fromhippocampal slices. Nano Lett. 2007, 7, 2188-2195.

[156] Allen, M.J.; Tung, V.C.; Kaner, R.B. Honeycomb carbon: a review of graphene. Chem. Rev., 2010, 110, 132-145.

1600 [167] Postma, H.C. Rapid sequencing of individual DNA molecules in grapheme nanogaps. Nano Lett., 2010, $10,420-425$.

[158] Tang, Z.; Wu, H. ; Cort, J.R.; Buchko, G.W. ; Zhang, Y.; Shao, Y.; Aksay, I.; Liu, J.; Lin, Y. Constraint of DNA on functionalized graphene improves its biostability and specificity. Small, 2010, 6, 12051209.

[159] Liu, Z.; Jiang, L.; Gali, F.; Nederlof, I.; Olsthoorn, R.L.; Lamers, C.M.; Oosterkamp, T.H.; Abrahams,

1610 J.P. A grapheme oxide_streptavidin complex for biorecognitione towards affinity purification. $A d v$. Funct. Mater., 2010, 20, 2857-2865.

[160] Song, Y.; Qu, K.; Zhao, C.; Ren, J.; Qu, X. Graphene oxide: intrinsic peroxidase catalytic activity and its 1615 application to glucose detection. Adv. Mater. 2010, $22,1-5$.

[161] Jung, J.H.; Cheon, D.S.; Liu, F.; Lee, K.B.; Seo, T.S. A graphene oxide based immunobiosensor for pathogen detection. Angew. Chem. Int. Ed., 2010, 49, 5708-5711.

[162] Mohanty, N.; Berry, V. Graphene-based singlebacterium resolution biodevice and DNA transistor: interfacing graphene derivatives with nanoscale and microscale biocomponents. Nano Lett., 2008, 8, 44694476.

[163] Zelada-Guillen, G.A.; Rius, J.; Duzgun, A.; Rius, 1685 F.X. Immediate detection of living bacteria at ultralow concentrations using a carbon nanotube based potentiometric aptasensor. Angew. Chem. Int.

$1630 \quad E d$., 2009, 48, 7334-7337.

[164] Yang, W.; Ratinac, K.R.; Ringer, S.P.; Thordarson, 1690 P.; Gooding, J.J.; Braet, F. Carbon nanomaterials in biosensors: should you use nanotubes or graphene? Angew. Chem. Int. Ed. 2010, 49, 2114-2138.

${ }_{35}$ [165] Liu, Z.; Robinson, J.T.; Sun, X.; Dai, H. PEGylated nanographene oxide for delivery of water-insoluble cancer drugs. J. Am. Chem. Soc., 2008, 130, 1087610877.

[166] Wang, Y.; Li, Z.; Hu, D.; Lin, C.T.; Li, J.; Lin, Y. Aptamer/graphene oxide nanocomplex for in situ molecular probing in living cells. J. Am. Chem. Soc., 2010, 132, 92746.

[167] Sun, Y.Q.; Wu, Q.; Shi, G.Q. Energy Environ. Sci., 2011, 4,1113 .

1645 [168] .Wang, W.; Li, F.; Zhao, J.P.; Ren, W.C.; Chen, Z.G.; Tan, J.; Wu, Z.S.; Gentle, L.; Lu, G.Q.; Chen, H.M. Fabrication of Graphene/Polyaniline Composite Paper via In Situ Anodic Electropolymerization for High Performance Flexible Electrode. ACS Nano, 2009, 3, 1745-1752.

[169] Yoo, J.; Balakrishnan, K.; Huang, J.; Meunier, V.; Sumpter, B.; Srivastava, A.; Conway, M.; Reddy, A.; Yu, J.; Vajtai, R.; Ajayan, P. Nano Lett., 2011, 11, 1423.

${ }_{1655}$ [170] Li, N.; Zhang, X.; Song, Q.; Su, R.; Zhang, Q,; Kong, T.; Liu, L.; Jin, G.; Tang, M.; Cheng, G. The promotion of neurite sprouting and outgrowth of mouse hippocampal cellsin culture by graphene substrates. Biomaterials, 2011,32, 9374-9382.

1660 [171] Gage, F.H. Mammalian Neural Stem Cells. Science, 2000, $287,1433-1438$.

[172] Conti, L.; Cattaneo, E. Neural stem cell systems: physiological players or in vitro entities? Nat. Rev. Neurosci., 2010, 11, 176-187.

1665 [173] Rothstein, J.D.; Snyder, E.Y. Reality and immortality-neural stem cells for therapies. Nat. Biotech., 2004, 22, 283.

[174] Zhao, C.; Deng, W.; Gage, F.H. Mechanisms and functional implications of adult neurogenesis. Cell, 2008, 132, 645-660.

[175] Ellis-Behnke, R.G.; Liang, Y.X.; You, S.W.; Tay, D.K.; Zhang, S.; So, K.F.; Schneider, G.E. Nano neuro knitting: Peptide nanofiber scaffold for brain repair and axon regeneration with functional return of vision. Proc. Natl. Acad. Sci. USA, 2006, 103, 50545059.

[176] Orive, G.; Anitua, E.; Pedraz, J.L.; Emerich, D.F. Biomaterials for promoting brain protection, repair and regeneration. Nat. Rev. Neurosci. 2009, 10, 682692.

[177] Silva, G.A.; Czeisler, C.; Niece, K.L.; Beniash , E.; Harrington, D.A.; Kessler, J.A.; Stupp, S.I. Science, 2004, 303, 1352-1355.

[178] Park, S.Y.; Park, J.; Sim, S.H.; Sung, M.G.; Kim, K.S.; Hong, B.H.; Hong, S. Enhanced Differentiation of Human Neural Stem Cells into Neurons on Graphene. Adv. Mater., 2011, 23, H263-H267.

[179] Heo, C.; Yoo, J.; Lee, S.; Jo, A.; Jung, S,; Yoo, H.; Lee, Y.H.; Suh, M. The control of neural cell-to-cell interactions through non-contact electrical field stimulation using graphene electrodes. Biomaterials, 
2011, 32, 19-27

[180] Feng, L.; Chen, Y.; Rena, J.; Qu, X. A graphene functionalized electrochemical aptasensor for 1695 selective label-free detection of cancer cells. Biomaterials, 2011, 32, 2930-2937.

[181] Green, R.A.; Lovell, N.H.; Wallace, G.G.; PooleWarren, L.A. Conducting polymers for neural interfaces: challenges in developing an effective long-term implant. Biomaterials, 2008, 29, 33933399.

[182] Chen, G.Z.; Shaffer, M.S.P.; Coleby, D.; Dixon, G.; Zhou, W.Z.; Fray, D.J.; Windle, A.H. Carbon nanotube and polypyrrole composites: coating and doping. Adv. Mater., 2000, 12, 522-526.

[183] Keefer, E.W.; Botterman, B.R.; Romero, M.I.; Rossi, A.F.; Gross, G.W. Carbon nanotube coating improves neuronal recordings. Nat. Nanotechnol., 2008, 3, 434943.

1710 [184] Peng, C.; Jin, J.; Chen, G.Z. A comparative study on electrochemical co-deposition and capacitance of composite films of conducting polymers and carbon nanotubes. Electrochimica Acta, 2007, 53,525-537.

[185] Bhandari, S.; Deepa, M.; Srivastava, A.K.; Joshi, 1715 A.G.; Kant, R. Poly(3,4-ethylenedioxythiophene)Multiwalled Carbon Nanotube Composite Films: Structure-Directed Amplified Electrochromic Response and Improved Redox Activity. J. Phys. Chem. B 2009, 113, 9416-9428.

${ }_{1720}$ [186] Lu, Y.; Li, T.; Zhao, X.; Li, M.; Cao, Y.; Yang, H.; Duan Y.Y. Electrodeposited polypyrrole/carbon nanotubes composite films electrodes for neural interfaces. Biomaterials, 2010, 31, 5169-5181.

[187] Luo, X.; Weaver, C.L.; Zhou, D.D.; Greenberg, R.;

${ }_{1725}$ Cui, X.T. Highly stable carbon nanotube doped poly(3,4-ethylenedioxythiophene) for chronic neural stimulation. Biomaterials, 2011, 32, 5551-5557.

[188] Supronowicz, P.R.; Ajayan, P.M.; Ullmann, K.R.; Arulanandam, B.P.; Metzger, D.W.; Bizios, R.J. Biomed. Mater. Res., 2002, 5, 499.

[189] Chao, T.; Xiang, S.; Chen, C.; Chin,W.; Nelson, A.J. Wang, C.; Lu, J. Carbon nanotubes promote neuron differentiation from human embryonic stem cells. Biochemical and Biophysical Research Communications, 2009, 384, 426-430.

[190] Nguyen-Vu, T.D.B.; Chen, H.; Cassell, A.M.; Andrews, R.; Meyyappan, M.; Li, J. Vertically aligned carbon nanofiber arrays: an advance toward electrical-neural interfaces. Small, 2006, 2, 89-94.

1740 [191] Li, J.; Andrews, R.J. Trimodal nanoelectrode array for precise deep brain stimulation: prospects of a new technology based on carbon nanofiber arrays. Operat. Neuromodulat., 2007, 537-545.

[192] McKenzie, J.L.; Waid, M.C.; Shi, R.; Webster, T.J.

1745 Decreased functions of astrocytes on carbon nanofiber materials. Biomaterials, 2004, 25, 13091317.

[193] Webster, T.J.; Waid, M.C.; McKenzie, J.L.; Price, R.; Ejiofor, J.U. Nano-biotechnology: carbon nanofibres as improved neural and orthopaedic implants. Nanotechnology, 2004, 15, 48. 